\title{
Properties and mechanisms of olfactory learning and memory
}

\author{
Michelle T. Tong ${ }^{1 *}$, Shane T. Peace ${ }^{2}$ and Thomas A. Cleland ${ }^{1}$ \\ 1 Computational Physiology Lab, Department of Psychology, Cornell University, Ithaca, NY, USA \\ ${ }^{2}$ Computational Physiology Lab, Department of Neurobiology and Behavior, Cornell University, Ithaca, NY, USA
}

\section{Edited by:}

Anne-Marie Mouly, Centre de Recherche en Neurosciences de Lyon, France

\section{Reviewed by:}

Justus V. Verhagen, The John B.

Pierce Laboratory, USA

Carolyn Harley, Memorial University

of Newfoundland, Canada

\section{*Correspondence:}

Michelle T. Tong, Department of

Psychology, Uris Hall, Cornell

University, Ithaca, NY 14853, USA

e-mail: tt389@cornell.edu
Memories are dynamic physical phenomena with psychometric forms as well as characteristic timescales. Most of our understanding of the cellular mechanisms underlying the neurophysiology of memory, however, derives from one-trial learning paradigms that, while powerful, do not fully embody the gradual, representational, and statistical aspects of cumulative learning. The early olfactory system-particularly olfactory bulb-comprises a reasonably well-understood and experimentally accessible neuronal network with intrinsic plasticity that underlies both one-trial (adult aversive, neonatal) and cumulative (adult appetitive) odor learning. These olfactory circuits employ many of the same molecular and structural mechanisms of memory as, for example, hippocampal circuits following inhibitory avoidance conditioning, but the temporal sequences of post-conditioning molecular events are likely to differ owing to the need to incorporate new information from ongoing learning events into the evolving memory trace. Moreover, the shapes of acquired odor representations, and their gradual transformation over the course of cumulative learning, also can be directly measured, adding an additional representational dimension to the traditional metrics of memory strength and persistence. In this review, we describe some established molecular and structural mechanisms of memory with a focus on the timecourses of post-conditioning molecular processes. We describe the properties of odor learning intrinsic to the olfactory bulb and review the utility of the olfactory system of adult rodents as a memory system in which to study the cellular mechanisms of cumulative learning.

Keywords: olfactory bulb, synaptic plasticity, generalization, representational learning, behavior

\section{INTRODUCTION}

Odor learning, like all learning, is distributed across multiple regions of the brain. Studies of learning within associative brain regions such as the hippocampus and prefrontal cortexparticularly in rodents - can utilize and manipulate olfactory stimuli just as they do other forms of sensory input (Eichenbaum et al., 1996; Eichenbaum, 1998; Law and Smith, 2012; Peters et al., 2013). Importantly, however, a substantial component of odor learning is intrinsic to the olfactory bulb (OB), and to its interactions with the piriform (olfactory) cortex to which $\mathrm{OB}$ mitral cells (second-order sensory neurons of the $\mathrm{OB}$ ) project (Figure 1). Within OB proper, several lines of evidence, including N-methyl-D-aspartate (NMDA)-based synaptic plasticity (Wilson, 1995; McNamara et al., 2008), the long-term potentiation of ascending piriform pyramidal projections onto OB granule cells (Gao and Strowbridge, 2009) and odor memory persistence linked to the selective retention of adult-born interneurons in the OB (Moreno et al., 2009; Kermen et al., 2010; Sultan et al., 2010) indicate that the OB itself supports sophisticated intrinsic plasticity mechanisms that regulate the transformation of olfactory signals across the first principal sensory synapse.
The elucidation of these intrinsic learning mechanisms within $\mathrm{OB}$ presents both theoretical and practical opportunities. While the OB is highly interconnected with multiple cortical and subcortical regions, it is morphologically isolated. This facilitates, for example, the specific delivery of neurochemicals or virallypackaged transgenes to the $\mathrm{OB}$ via cannulation. The neural circuitry of the $\mathrm{OB}$ and the physiology of its diverse neurons are reasonably well-described (Figure 1), enabling the development of biophysically realistic models of $\mathrm{OB}$ function that can associate specific cellular properties and mechanisms with systems-level function and performance (Migliore and Shepherd, 2002; Li and Cleland, 2013). Specific odor-dependent behavioral paradigms have been developed that are strongly sensitive to OB manipulations and are likely to depend on $\mathrm{OB}$ intrinsic learning, enabling some segregation of OB-specific learning from odor learning dependent on other brain regions (Wilson and Linster, 2008). As the direct target of primary sensory neurons, the $\mathrm{OB}$ responds to, and differentiates among, the physical stimulus representations of odorants, but also closely apposes these bottom-up inputs with powerful top-down state-dependent and neuromodulatory influences. The olfactory system thus provides a powerful model to study representational learning (Bieszczad and Weinberger, 


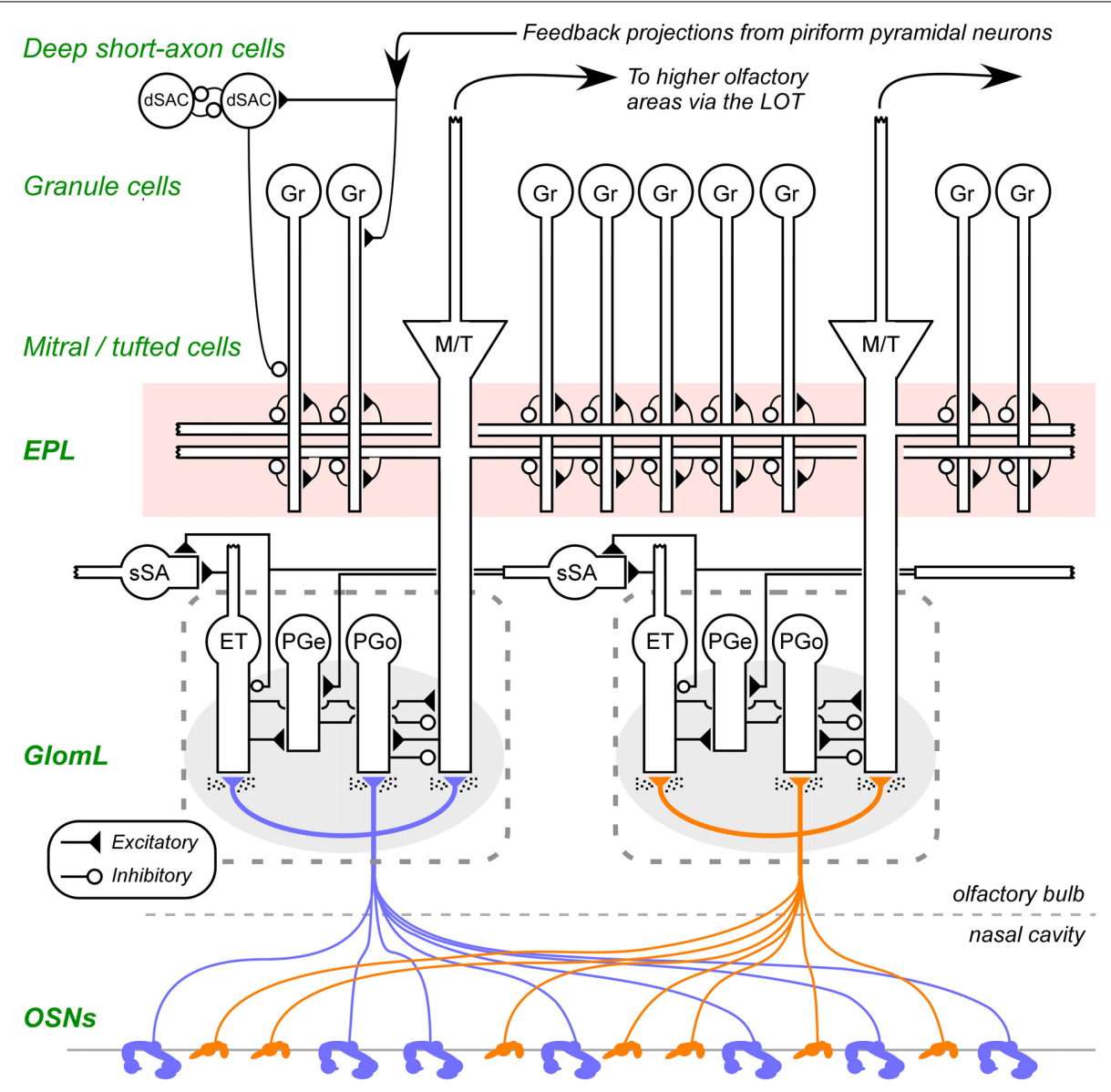

FIGURE 1 | Circuit diagram of the mammalian olfactory bulb. The axons of olfactory sensory neurons (OSNs) expressing the same odorant receptor type converge and arborize together to form glomeruli (shaded ovals; two depicted) on the surface layer of the olfactory bulb. Intrinsic OB interneurons innervate each glomerulus, including olfactory nerve driven periglomerular cells (PGo), external tufted cell-driven periglomerular cells (PGe), and external tufted cells (ET). Superficial short-axon cells (sSA), closely related to PG cells and possibly part of the same heterogeneous population, are not associated with specific glomeruli but project broadly and laterally within the deep glomerular layer. Principal neurons include mitral cells and tufted cells (collectively depicted as $M / T$ ), which interact via reciprocal connections in the external plexiform layer (EPL) with the dendrites of inhibitory granule cells $(\mathrm{Gr})$, thereby receiving recurrent and lateral inhibition, and project out of the OB to several regions of the brain. The heterogeneous deep short-axon cell population (dSAC) includes cells that deliver GABAergic inhibition onto granule cells and one another, and, along with granule cells, receive centrifugal cortical input from piriform pyramidal cells. OE, olfactory epithelium (in the nasal cavity); GL, glomerular layer; EPL, external plexiform layer; $\mathrm{MCL}$, mitral cell layer; $\mathrm{IPL}$, internal plexiform layer; GCL, granule cell layer. Filled triangles denote excitatory synapses; open circles denote inhibitory synapses. Speckles surrounding OSN terminals denote volume-released GABA and dopamine approaching presynaptic $G_{A B A}$ and dopamine D2 receptors. Note that sSA-PG and SSA-sSA synapses are depicted as excitatory despite being GABAergic (discussed in Cleland, 2014). Figure adapted from Cleland et al. (2012).
2010) - that is, the integrated effects of learning on the forms (or shapes) of neural representations as well as their persistence (see section 2.1). However, the OB remains underdeveloped as a model system for the neuroscientific study of learning and memory circuits. Critical elements such as the factors influencing memory persistence, the mechanistic differences between associative and nonassociative conditioning, and the signature molecular mechanisms of cellular and synaptic learning have been observed in $\mathrm{OB}$ but require further exploration. We here outline the features of OB-dependent intrinsic learning and review work on the structural and molecular mechanisms of memory formation, with a focus on the timecourses of learning-initiated signaling cascades and the roles of extracellular signals such as classical neuromodulators and the peptide brain-derived neurotrophic factor (BDNF). In particular, we discuss how research into representational, appetitive and cumulative learning mediated by plasticity in the olfactory system can most productively contribute to a broad understanding of general learning and memory mechanisms.

\section{LEARNING IN THE OLFACTORY BULB 2.1. ODOR LEARNING IS REPRESENTATIONAL}

Learning alters the transformation of information by a neural circuit, and memory refers to the persistence of that altered transformation function over time. In olfactory representational learning, the forms of odor representations are sensitive to learning 
and can be measured using behavioral generalization gradients (Cleland et al., 2002, 2009; Fernandez et al., 2009). Olfactory generalization gradients define the range of variance in odor quality that an animal will respond to as representative of a given odor, and reflect the statistical reliability of odor features (Wright and Smith, 2004). The area under the gradient, or consequential region (Shepard, 1987), describes the degree of certainty expressed by the animal that a stimulus of a given quality is likely to represent that learned odor or its implications. Increased pairings of odor with reward progressively sharpen the generalization gradient (Figure 2A), and manipulations of other training parameters indicate that factors that increase classical learning also increase the rate of sharpening of olfactory generalization gradients (Cleland et al., 2009). If the odor being paired with reward is itself variable in quality, however, it becomes clear that the generalization gradient does not sharpen per se, but progressively conforms to the actual environmental distribution of reward-predicting odor qualities as experienced by the animal (Cleland et al., 2012, Figure 2B). That is, the learning-dependent regulation of generalization gradients describes a statistical learning process by which an animal's internal odor representations become gradually and probabilistically categorical (Tenenbaum and Griffiths, 2001), evolving to correctly reflect the meaningful categories of the external olfactory environment (Cleland et al., 2012). This aspect of odor learning has been hypothesized to rely on OB circuitry both for theoretical reasons and based on results from the experimental manipulation of $\mathrm{OB}$ circuit function (Mandairon et al., 2006; Guérin et al., 2008; McNamara et al., 2008; Linster and Cleland, 2010; Devore and Linster, 2012; de Almeida et al., 2013; Dillon et al., 2013). Hence, in contrast to odorants-which are chemical stimuli, whether simple or complex-odors here are psychometrically defined as probability density functions of odorant quality that the animal has learned imply the same consequences, embedded within a high-dimensional similarity space that is best defined by odorant receptor activation levels (Cleland, 2008,
2014). Behaviorally-measured generalization gradients constitute one-dimensional trajectories within this high-dimensional space, essentially estimating the changing form of the odor representation via sampling. The key point is that memory content is not a constant, but changes with learning and over time just as memory strength and persistence do. By providing quantifiable, interpretable measures of memory content as it evolves, odor generalization gradients illustrate the advantages of representational learning systems for the study of learning and memory mechanisms.

\subsection{APPETITIVE ODOR LEARNING IS CUMULATIVE AND INCREMENTAL}

The cellular and synaptic neurophysiology of mammalian learning and memory is substantially based on fear conditioning. The advantage of the conditioned fear model is that strong, discrete, and easily measurable memories can be generated by single learning trials, avoiding the complexity and additional questions imposed by the need to integrate the cumulative effects of multiple learning events. The persistence of these memories is a function of the unconditioned stimulus amplitude-e.g., footshock current-but commonly extends to several days (Bekinschtein et al., 2007), enabling study of the sequential transitions in their structural, biochemical, and molecular substrates that occur over time. The clearest example of these gradually transforming dependencies is the protein synthesis requirement for long-term (many hours to days or more) but not short-term (up to a few hours) memory (Davis and Squire, 1984; DeZazzo and Tully, 1995), though additional phases of memory have been defined in some systems. Moreover, many specific cellular signaling cascades, induced by fear conditioning events and underlying the relevant learning, have been described; whereas most of these processes are initiated immediately after the causal event, several have been described that are initiated minutes or even hours later (Figure 3).

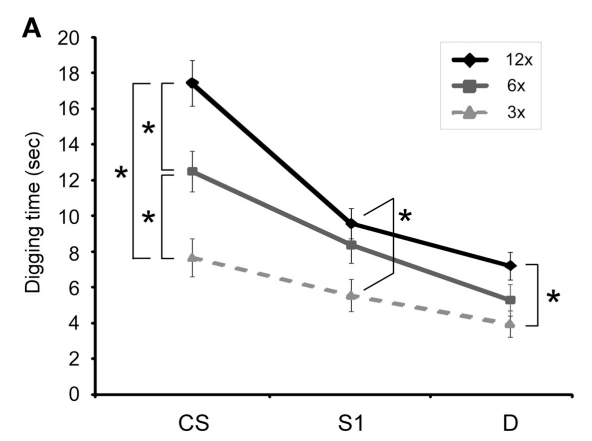

FIGURE 2 | Olfactory generalization gradients in mice. (A) Mice received either 3,6 , or 12 pairings of an odor CS with buried reward, after which their perseverance in digging following randomized presentation of the odor CS, a similar odorant (S1) and a dissimilar odorant (D) was measured. Increasing the number of training trials prior to testing progressively increased perseverance and sharpened associative generalization gradients. $3 x$ : three training trials; $6 x$ : six training trials; $12 x$ : 12 training trials. Asterisks denote significant pairwise differences. Figure adapted from Cleland et al. (2009). (B) Generalization

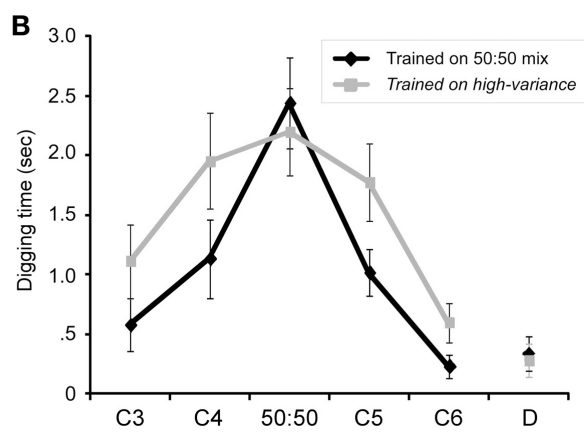

gradients adapt to the variance of the conditioning odor. Mice received 12 pairings of an odor CS with buried reward; this CS was either a 50:50 mixture of odorants C4 and C5 (Trained on 50:50 mix group) or was a variable mixture of the same two odorants, varying from 95:5 to 5:95 on different trials (Trained on high variance group). The high-variance training group generalized significantly more broadly than the low-variance training group. Abscissa comprises a sequentially-similar homologous series of different odorants (C3, C4, C5, C6) and a dissimilar odorant (D). Figure adapted from Cleland et al. (2012). 


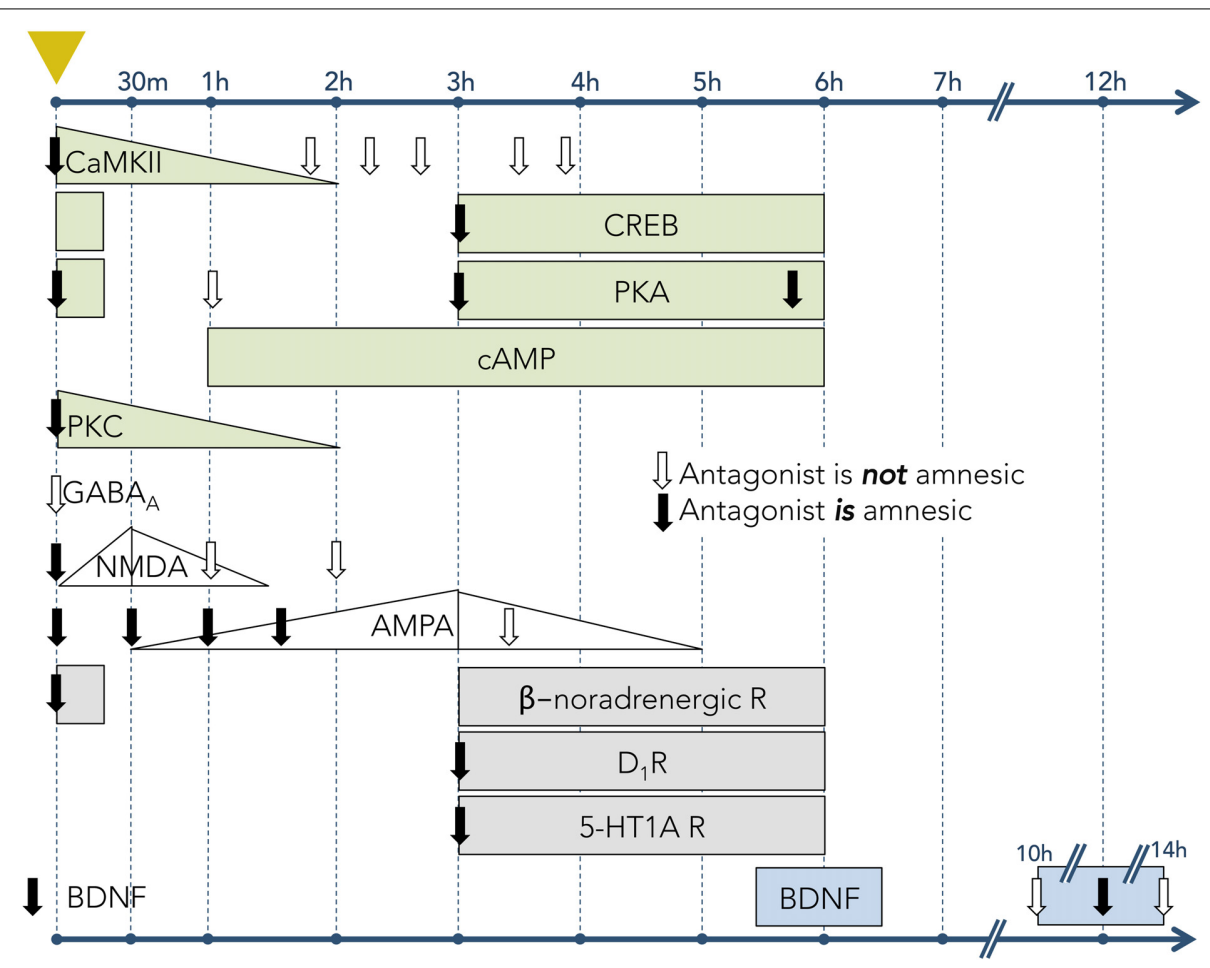

FIGURE 3 | Timecourses of activity for learning-associated molecular mechanisms in hippocampal tissue following one-trial inhibitory avoidance (IA) training. Leftmost dashed vertical line (marked with yellow triangle) denotes the time of IA conditioning. Subsequent vertical lines denote timepoints following the trial. Rows correspond to particular mechanisms (signaling molecule, receptor, or neuromodulator). Downward-pointing arrows indicate timepoints when antagonists to the corresponding receptor or signaling pathway were infused into the hippocampus; solid arrows denote that the antagonists had an amnesic effect on LTM (when tested 24-48 h after conditioning); open arrows indicate no amnesic effect on LTM. Filled shapes denote the experimentally-measured expression levels of receptors or signaling molecules. Increasing or decreasing levels are depicted when known; rectangles depict measurable levels when relative abundances were not measured. Light green shapes represent intracellular signaling pathways, including Ca2+/calmodulin-dependent protein kinase II (CaMKII), cAMP response element-binding protein (CREB), protein kinase $A(P K A)$, cyclic adenosine monophosphate (cAMP), and protein kinase C (PKC) (Data from: Jerusalinsky et al., 1994; Wolfman et al., 1994; Bernabeu et al., 1996, 1997a,b; Bevilaqua et al., 1997; Cammarota et al., 1997; Izquierdo et al., 1997). White shapes represent ionotropic receptors for neurotransmitters, including $\gamma$-Aminobutyric acid $\mathrm{A}\left(\mathrm{GABA}_{\mathrm{A}}\right)$ receptors, $\mathrm{N}$-methyl-D-aspartate (NMDA) receptors, and $\alpha$-amino-3-hydroxy-5-methyl-4-isoxazolepropionic acid (AMPA) receptors (Data from: Izquierdo et al., 1992; Jerusalinsky et al., 1992; Bernabeu et al., 1997c). Gray shapes represent the activity of receptors for neuromodulators, including $\beta$-noradrenergic receptors, dopamine type 1 receptors $\left(D_{1} R\right)$, and serotonin $1 A$ receptors $(5-H T 1 A)$ (Data from: Izquierdo et al., 1992; Bernabeu et al., 1996; Bevilaqua et al., 1997). Blue shapes represent brain-derived neurotrophic factor (BDNF; Data from Bekinschtein et al., 2007).
Olfactory appetitive learning, in contrast, is gradual, cumulative, and statistical (Cleland et al., 2009, 2012, Figure 2). The richness of the OB learning model that is gained by its statistical and representational character also imposes a cost in terms of unavoidable complexity. For example, the distribution of repeated training events in time will always be a factor; massed versus spaced learning schedules are well known to affect memory persistence (Tsao, 1948; Menzel et al., 2001; Kermen et al., 2010), and intertrial interval timing can even determine which areas of the brain are most immediately responsible for nonassociative odor learning (McNamara et al., 2008). This complexity, however, is manageable, and is substantially mitigated by the theoretical tractability and experimental accessibility of the $\mathrm{OB}$ as well as the elucidation of plasticity-related molecular cascades in other cortical memory systems. Studies of representational plasticity and memory processes in primary and secondary sensory cortices offer a singular opportunity to understand a new dimension of memory-plasticity in form as well as persistence-in preparations within which its form can be measured physiologically as well as psychophysically (Bieszczad and Weinberger, 2010). This is critical for a mechanistic understanding of statistical learning, in which repeated stimulus experiences are not identical and part of the challenge of learning is to estimate the intrinsic variability of meaningful stimuli and the relationship between stimulus quality and outcome.

It is worth noting that odor learning in $\mathrm{OB}$ is not always gradual and cumulative. Fear conditioning to odorants induces strong one-trial learning, which appears to involve plasticityrelated molecular changes in the OB (Jones et al., 2007). However, this aversive learning appears to substantially broaden olfactory generalization, rather than sharpen it as is observed in appetitive odor learning (Chen et al., 2011). This can be interpreted as adaptive, in that broad generalization is the safe, conservative response to a dangerous odor of uncertain variance, but it raises important 
mechanistic questions: what would be the cumulative effect of multiple aversive conditioning trials, for example, or how would this broad generalization gradient interact with strong, preexisting, non-aversive odor representations? It also suggests that the mechanisms underlying the effects of aversive conditioning in $\mathrm{OB}$ may differ qualitatively from those underlying appetitive conditioning at some level of organization.

Odor learning in neonates also is qualitatively different from that described in adults. First, neonatal odor learning is more heavily OB-dependent than it is in adults, in part because downstream learning areas such as the amygdala are not yet functional (Berdel et al., 1997; Sullivan, 2003). Second, neonatal odor learning is substantially stronger and less conditional than it is in adults, exhibiting a nearly all-or-none quality that contributes to the rapid learning of maternal and nest odors (Sullivan et al., 1991, 2000). Accordingly, studies of the molecular cascades and mechanisms underlying intrinsic $\mathrm{OB}$ learning are most advanced in neonates (McLean and Harley, 2004; McLean et al., 2005; Grimes et al., 2012; Lethbridge et al., 2012). Many of these mechanisms, however, are likely to be conserved in some form to underlie the incremental appetitive learning exhibited by adults. For example, norepinephrine (NE) and the intracellular cascades that it initiates play a central role in neonatal olfactory learning (Sullivan et al., 1989; Yuan et al., 2003). Indeed, the innate hyperresponsivity of the neonatal locus coeruleus (LC) is the underlying mechanism of one-trial odor learning in neonates (Sullivan, 2001, 2003; Moriceau and Sullivan, 2005), and NE delivery to the $\mathrm{OB}$ is sufficient to induce odor preference learning in neonates (see section 4.1). In adults, in contrast, LC responsivity is much more measured and conditional. Nevertheless, NE in the adult $\mathrm{OB}$ is essential for even the basic nonassociative learning processes underlying odor habituation (Guérin et al., 2008; Shea et al., 2008; Moreno et al., 2012), and selective NE receptor antagonists infused into $\mathrm{OB}$ impair conditioned odor preference learning, recognition memory, and near-threshold odor identification (Guérin et al., 2008; Escanilla et al., 2010, 2012; Linster et al., 2011; Manella et al., 2013). In this way, the cellular mechanisms of memory elaborated by one-trial learning paradigms can serve as the basis for study of the more complex problem of ongoing appetitive learning.

\subsection{ADVANTAGES OF OLFACTORY BULB LEARNING MODELS}

The OB provides both practical and theoretical advantages for study of the molecular and structural mechanisms involved in memory. Practically, pharmacological agents can be infused selectively and locally into the OB. Intrinsic OB circuits display functional plasticity similar to other regions of the brain, including long-term synaptic potentiation (Gao and Strowbridge, 2009) and adult neurogenesis (Lledo et al., 2006), and are reconfigured substantially by neuromodulatory inputs (Devore and Linster, 2012). Established behavioral paradigms enable insight into the changing form as well as the persistence of odor representations over time, and physiological studies enable measurements of direct correspondence between environmental changes, behavioral performance, and the synaptic and molecular changes that occur in neural circuitry (Abraham et al., 2012, 2014; Qiu et al., 2014). In particular, odor learning exhibits varying memory durations that are related to behavioral task parameters and depend on evolving physiological substrates for short-term memory (Figure 4; McNamara et al., 2008), intermediate-term memory (Grimes et al., 2011), and long-term memory (Figure 5; Lazarini and Lledo, 2011).

\subsubsection{Habituation and cross-habituation}

In this non-associative olfactory learning paradigm, animals first are habituated to an odorant, responding to repeated presentations with progressively lower investigation times. Some time after habituation, they are presented again with that odorant, or with a series of structurally and perceptually similar odorants (cross-habituation, also referred to as spontaneous discrimination). Perceptually distinct odors elicit normal, non-habituated investigation times, but odorants similar to the habituated odorant elicit reduced, partially-habituated responses depending on the degree of similarity between the habituated and test odorants. A generalization gradient therefore can be constructed by presenting a battery of similar odorants to habituated animals and measuring the pattern of cross-habituation among odorants (Cleland et al., 2002). Interestingly, memory for odorant habituation acquired on short timescales (tens of seconds) is predominantly mediated within piriform cortex (Wilson, 2009), whereas habituation on the minutes timescale is localized within $\mathrm{OB}$ (McNamara et al., 2008; Chaudhury et al., 2010). Habituation and cross-habituation memory persistence is sensitive to the degree of habituation, declining over a $10-20 \mathrm{~min}$ period in standard protocols (Freedman et al., 2013). Both the extent and persistence of cross-habituation memory are regulated by neuromodulatory and hormonal effects in the $\mathrm{OB}$ as well as task parameters and

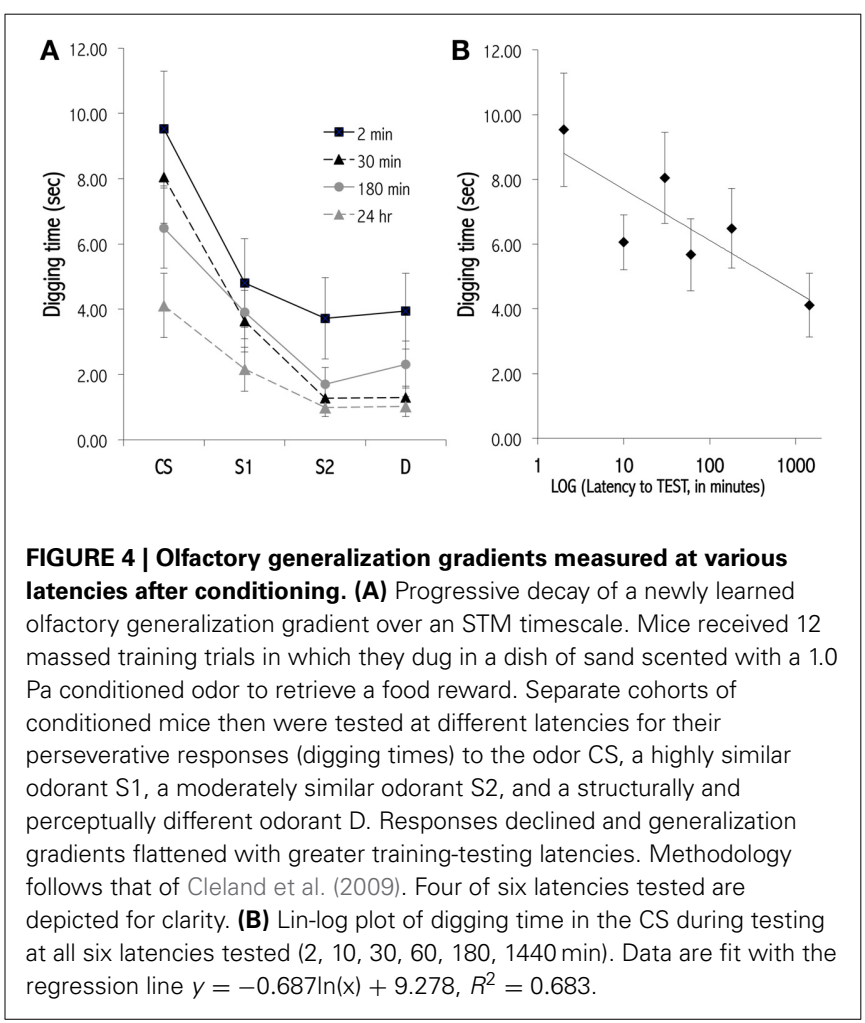



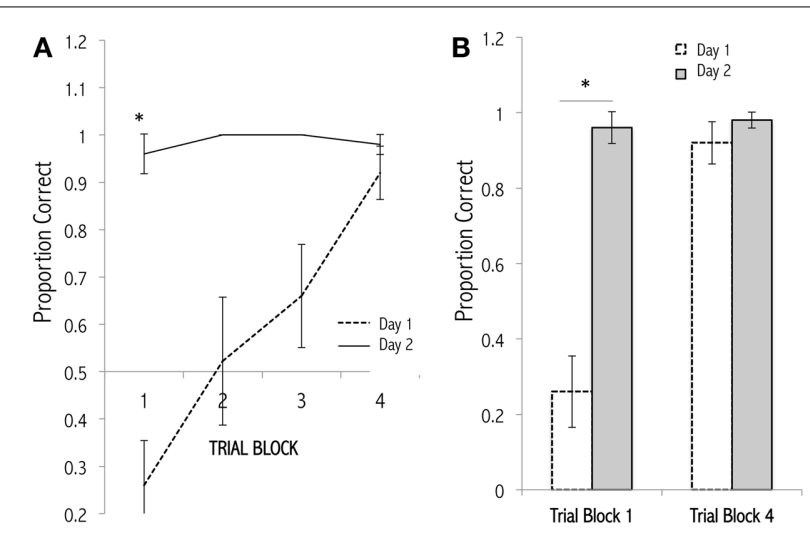

FIGURE 5 | Learning curves for an odor discrimination task. (A) Mice received 20 trials of discrimination training (Cleland et al., 2002) in which they learned to choose a rewarded conditioned odor (1.0 Pa) over a distractor odor (Day 1). Twenty-four hours later, the discrimination training was repeated (Day 2). The correct trials were scored and averaged across animals. Trials are grouped into 4 blocks of 5 consecutive trials for display and analysis. A steady improvement across trials on Day 1 is remembered 1 day later. (B) Data from trial blocks 1 and 4 replotted for comparison. Comparing trial block 1 (trials 1-5) between days, mice performed significantly better on the second training session, indicating a robust retention of odor memory [asterisk: $t(8)=7.5593, p<0.001$ ]; no other comparisons approach statistical significance. Comparable findings have been observed by Schellinck et al. (2001).

state variables (Mandairon et al., 2006, 2008; Dillon et al., 2013; Manella et al., 2013).

\subsubsection{Associative generalization}

Generalization gradients also can be measured in response to odorants that are conditioned via associative pairing with reward (Cleland et al., 2002, 2009). After conditioning, animals are tested with batteries of structurally and perceptually similar odorants, often in a digging task where the odorant cue signals a buried reward. The animals' perseverance, measured as time spent digging, in pursuit of an expected reward (that is not present in test trials) declines with increasing perceptual dissimilarity between the conditioned and test odorants. The breadths and forms of these gradients are sensitive to determinants of learning and to the statistical variance in odorant CS quality across conditioning trials (Cleland et al., 2009, 2012) and also are sensitive to the pharmacological and neuromodulatory manipulation of $\mathrm{OB}$ circuitry (Zimering and Cleland, 2011). Associative odor learning based on a standard short-term conditioning paradigm (a single series of up to twelve massed conditioning trials) progressively decays over a timescale of several hours (Figure 4), though this timescale is likely to be sensitive to training parameters.

\subsubsection{Odor discrimination}

Odor discrimination is the most commonly used olfactory learning model, and subsumes many radically different conditioning paradigms and performance metrics. The distinguishing feature of this task is that animals are motivated to distinguish between two or more odors with different learned contingencies (e.g., one is rewarded and the other not), such that it tends to measure an animal's capacity to learn a given discrimination rather than to measure an odor representation per se. Automated tasks with relatively nonintuitive metrics (e.g., odor-specified left-right selection or go/no-go tasks) may utilize hundreds of training trials, whereas tasks with more intuitive (to the animal) metrics such as odor-cued digging often require less than 20 trials to reach criterion. The dependence of odor discrimination performance on OB circuitry corresponds closely with the difficulty of the discrimination (Rinberg et al., 2006), which corroborates theoretical proposals that $\mathrm{OB}$ circuitry serves in large part to identify which statistical differences among inputs correspond to meaningfully different odorants, and which are simply variations of a single odor that should be generalized (Cleland et al., 2012).

\subsubsection{Olfactory performance depends on memory}

In olfaction, memory does not serve only to remember odors past, but is also a critical factor in realtime perceptual processing, even within OB and piriform cortex (Wilson and Stevenson, 2003a,b; Zucco et al., 2014). Hence, short-term and long-term memory processes are likely to be highly interactive and conditional; e.g., the form of a long-term memory should acquire the evolving characteristics of accumulating short-term memory processes during multitrial odor learning tasks or natural learning scenarios. That is, though it is established in general that STM and LTM processes are initiated separately-i.e., LTM is not simply a continuation of STM (Figure 6; Izquierdo et al., 1999) - it also is true that LTM must be able to be repeatedly updated based on new information even before it is first behaviorally expressed. One likely scenario is that short-term learning and memory processes contribute to this updating-a hypothesis that the olfactory appetitive learning and memory model is well-poised to test.

\section{MOLECULAR AND STRUCTURAL MECHANISMS OF LEARNING AND MEMORY}

Memory mechanisms are heterogeneous in form, structure, and timecourse, yet exhibit many commonalities across regions of the brain. We here separate these mechanisms into two broad categories: molecular, which includes intracellular cascades, molecular signaling, neuromodulatory influences, activity-dependent protein synthesis, and epigenetic modifications, and structural, which includes physiological changes such as long-term potentiation or other synaptic weight modifications, alterations to neuronal morphology such as dendritic branching, changes to terminal shapes or numbers, and ancillary modifications such as effects on glia or cell adhesion to the extracellular matrix, as well as changes to neuron number via adult neurogenesis or selective apoptosis. Mechanisms from these categories often are interdependent, and exhibit characteristic response timecourses that underlie memory-related changes. In this section, we review selected learning models and mechanisms drawn primarily from the hippocampal literature, focusing on models with well-developed response timecourses and signaling mechanisms for which there is evidence of relevance to OB learning as well.

\subsection{MOLECULAR MECHANISMS}

Inhibitory avoidance (IA) is a well-established behavioral paradigm for one-trial fear conditioning that offers a simple 


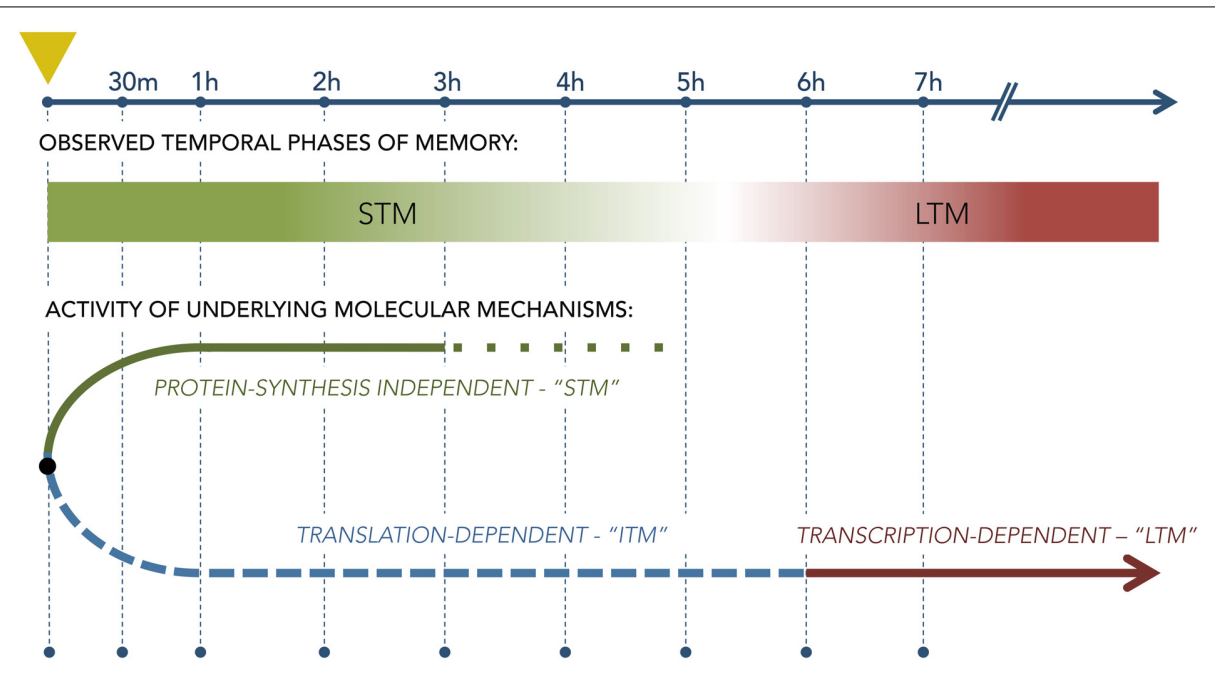

FIGURE 6 | Diagram of the separate molecular pathways underlying short-term and long-term memory as derived from studies using single-trial aversive training paradigms. Leftmost dashed vertical line (marked with yellow triangle) denotes the the time of conditioning; subsequent vertical lines denote timepoints following the trial. The lower diagram illustrates the theoretical bifurcation of memory mechanisms into a protein synthesis-independent STM stream that governs behavior for the first few hours after training and a separate, protein synthesis-dependent LTM stream that begins to govern behavior only thereafter. The relationship, if any, between these two streams during multiple repeated conditioning trials is not clear. analog measure of memory "strength." IA memories can persist strongly for days, enabling study of both short-term and longterm memory mechanisms. If entering a darkened chamber or stepping down from a platform results in footshock on the conditioning trial, a normal animal will hesitate, in subsequent test trials, before again entering that chamber or stepping down. The delay in seconds before again entering the chamber or stepping down is a robust measure of the strength of the actionconsequence association. Much of what is known about the molecular mechanisms of memory and their timecourses in mammalian systems has been developed using this task.

\subsubsection{Long-term memory}

IA conditioning leads to a rapid elevation in calcium/calmodulindependent protein kinase II (CaMKII) levels in the hippocampus. This in turn enhances the phosphorylation of cyclic AMP (cAMP) response element binding protein (CREB) (Miyamoto, 2006) and promotes the formation of complexes with ionotropic glutamate NMDA receptors (Sanhueza and Lisman, 2013), which have been shown to play a functional role in learning and memory (reviewed in Danysz et al., 1995). Blocking CaMKII activity immediately after IA training substantially reduced animals' fear responses when measured $24 \mathrm{~h}$ later (i.e., LTM). However, blocking CaMKII activity $30 \mathrm{~min}$ after IA resulted in a weaker LTM deficit, and blockade 2-4 h after IA had no effect on LTM at all (Figure 3; Wolfman et al., 1994). These findings indicate that CaMKII plays a crucial role early in the memory induction process, and that its functional role in LTM formation is confined to a specific period following learning. The neurotrophin BDNF also plays a critical signaling role in LTM induction (Figure 3). For example, blockade of BDNF signaling through its TrkB receptor, or through function-blocking anti-BDNF, disrupted LTM but not STM for a conditioned IA event, whereas infusion of recombinant BDNF into hippocampus rescued IA memory from amnesia induced by glucocorticoid receptor blockade (Chen et al., 2012).

Other studies have demonstrated the early involvement of the cAMP-protein kinase A (PKA)-CREB pathway in LTM formation. Cyclic AMP levels in the hippocampus begin to rise about $30 \mathrm{~min}$ following IA training, peak at $3 \mathrm{~h}$ after training, and decrease to baseline levels circa $6 \mathrm{~h}$ after training (Bernabeu et al., 1996, 1997a). PKA activity and CREB phosphorylation (pCREB levels), in contrast, both exhibit two distinct peaks: one immediately following training and another beginning roughly $3 \mathrm{~h}$ thereafter and persisting until $6 \mathrm{~h}$, but not $9 \mathrm{~h}$, post-conditioning. The second of these peaks coincides with peak hippocampal cAMP levels (Bernabeu et al., 1997a). Injection of the PKA inhibitor KT5720 into the hippocampus 0-6h after conditioning impairs IA memory when tested $24 \mathrm{~h}$ after training (Bernabeu et al., 1997a). Similarly, injections of CREB antisense oligonucleotides into the amygdala impaired LTM in the IA task (Canal et al., 2008), and infusions of antisense CREB oligonucleotides into the hippocampus prior to water maze training blocked 48h LTM while sparing 4-h STM (Guzowski and McGaugh, 1997). Mutant mice that lack the $\alpha$ and $\beta$ isoforms of CREB also exhibit impaired LTM consolidation, but normal STM, on a contextual fear conditioning task (Bourtchuladze et al., 1994).

In a multi-trial, appetitive learning paradigm based on the radial arm maze task, increased PKA activity and CREB phosphorylation levels were observed in the hippocampus after the fourth consecutive day of training, but not after the first day, in contrast to the immediate same-day effects observed in IA studies (Mizuno et al., 2002). A similar contrast between IA conditioning and appetitive learning effects has been described with learning-associated BDNF activation. Infusions of functionblocking anti-BDNF antibody into the hippocampus prior to, but not $6 \mathrm{~h}$ after, IA training block LTM, indicating that BDNF 
activity around the time of learning sets the stage for eventual LTM consolidation (Alonso et al., 2002). In contrast, on an appetitive radial arm maze task, BDNF mRNA levels in hippocampus increased only after 8 , but not 4 , consecutive days of conditioning, and even then mRNA levels were significantly elevated only after $15 \mathrm{~min}$, but not immediately, following training (Mizuno et al., 2002). A similar increase in BDNF mRNA levels, with a comparable 15-min delay, also was observed after 28 days of training with this task (Mizuno et al., 2000). (It remains unclear whether the levels observed at 8 and 28 days represent a continuous elevation in task-induced BDNF mRNA transcription across those days or reflect multiple peaks in BDNF mRNA activity). These findings suggest that similar molecular mechanisms can mediate multi-trial appetitive learning as underlie fear-based single-trial learning, but that the timecourses can differ. It is in these latter contingencies that the richness of appetitive learning studies is likely to contribute most significantly to general studies of learning and memory. Should LTM be modeled as a statistical evidence accumulation system, in which LTM is formed only after enough evidence has accumulated that the cue-reward association is reliable and likely to remain true over time? How is this compatible with the evidence that, in IA training, LTM induction is initiated immediately after learning (and is not dependent upon intact STM), even though it cannot govern behavioral responses until hours later? Once LTM is induced, how is the persistence of that memory governed? How does existing LTM contribute to STM formation over multi-day training sequences? What factors contribute to the timescales, selectivity, and stringency of new memory formation?

\subsubsection{Short-term memory}

The formation and maintenance of short-term memory (STM), which are independent of protein synthesis, rely on different molecular mechanisms than those underlying LTM (Izquierdo et al., 1999). To elucidate these different mechanisms, animals were conditioned using the IA protocol, immediately infused with one of a battery of antagonists into the hippocampus, and behaviorally tested for memory retention at $1.5 \mathrm{~h}$ (STM) and $24 \mathrm{~h}$ (LTM) after training (Izquierdo, 2000). The study showed that STM formation required cyclic GMP (cGMP), mitogenactivated protein kinase kinase (MAPKK), and PKA, but did not depend on protein kinase $G(P K G)$, protein kinase $C(P K C)$, or CaMKII. (Note that this dependence of STM on PKA differs from the PKA-independent STM of neonatal OB as described above). Additionally, infusions of either an AMPA receptor antagonist or a $\gamma$-aminobutyric acid (GABA) subtype A receptor agonist into the entorhinal cortex prior to training impaired STM when tested at $1.5 \mathrm{~h}$ following training, but did not impair LTM when tested $24 \mathrm{~h}$ after conditioning (Izquierdo et al., 1998). Critically, these results demonstrated that LTM does not derive from STM representations, in that LTM formation does not depend on intact STM. Instead, at least two distinct cascades of events are set in motion after training (Figure 6), one of which enables rapid behavioral adjustment but decays in several hours (STM), and the other of which is longer-lasting but cannot be behaviorally expressed for the first few hours after conditioning (LTM). Interestingly, the distinct STM and LTM pathways - and many of their mechanistic elements - are common across widely divergent clades, including mollusks and insects as well as vertebrates (Davis and Squire, 1984; DeZazzo and Tully, 1995; Blum et al., 2009), suggesting that these properties have been strongly conserved.

A distinct, intermediate phase of memory, termed intermediate-term memory (ITM), also has been defined, originally in Aplysia californica. It is characterized primarily by its dependence on protein translation but not on transcription (Sutton et al., 2001, 2002), although a separate, mechanistically distinct form of ITM in Aplysia also has been described (Sutton et al., 2004). Though the timescales of these memory phases in Aplysia differ from their mammalian analogs, a translationdependent, transcription-independent ITM for conditioned odor preference also has been identified in neonatal rat OB (Grimes et al., 2011). Infusion of anisomycin, a translation blocker, immediately after conditioning had no effect on odor memory when the rat pups were tested one or $3 \mathrm{~h}$ later, but eliminated the memory when tested 5 or $20 \mathrm{~h}$ after conditioning. When actinomycin, a transcription blocker, was similarly infused, memory at 1,3 , and $5 \mathrm{~h}$ was comparable to control animals, but an impairment of odor memory was observed at $24 \mathrm{~h}$. It is likely that the mechanism underlying memory during this intermediate period ( $\sim 5 \mathrm{~h}$ after conditioning) is simply the LTM mechanism; that is, it is in this time window that new proteins begin to be required for memory maintenance, but the translation of existing mRNA transcripts provides a sufficient supply for a limited time. This interpretation is supported by subsequent results demonstrating that PKA blockade blocks 5-h ITM and 24-h LTM, but not 3-h STM (Grimes et al., 2012).

\subsection{STRUCTURAL MECHANISMS}

Long-term memory has long been associated with persistent structural changes in specific brain regions involved in the formation of the memory. Many of the molecular mechanisms characterized in LTM induction and maintenance also have been shown to influence these structural changes, which may in some cases be the primary effectors of the memory. We briefly review some of these structural mechanisms here.

\subsubsection{Long-term potentiation}

Over decades of research, considerable debate has arisen about whether, and to what extent, long-term synaptic potentiation (LTP, Bliss and Lømo, 1973) underlies or otherwise corresponds to behaviorally-measured LTM (Izquierdo, 1993). The arguments in favor of their relationship were strengthened by the elucidation of two distinct forms of hippocampal long-term plasticity (LTP), a short-duration early form (E-LTP) and a longer-lasting late form (L-LTP) distinguished primarily by the latter's dependence on protein synthesis. Specifically, the persistence of LTP in the CAl region beyond roughly $4 \mathrm{~h}$ depends on mRNA and protein synthesis (Frey et al., 1988; Bliss and Collingridge, 1993); translation blockers injected into rat dentate gyrus during in vivo LTP induction caused synaptic potentiation to decay within 3-4 h (Krug et al., 1984). This timescale closely resembles the proteinsynthesis dependency of LTM observed in behavioral studies. Similarly, after LTP induction by a tetanic stimulation of afferent fibers in hippocampal slices, any further tetanus to the afferent 
within $3 \mathrm{~h}$ generates only short-term plasticity across the synapse, whereas after $4 \mathrm{~h}$ the same tetanus could generate a longer-lasting potentiation over and above the initially induced LTP level (Frey et al., 1995). The timescale of this effect also corresponds with the STM/LTM distinctions described above, and additionally suggests that LTM expression may free up resources needed for further learning. Finally, several molecular mechanisms associated with memory induction and persistence also regulate LTP. For example, CaMKII activity is necessary for LTP induction (Malinow et al., 1989), PKC inhibition immediately following induction leads to early decay of potentiation (Wang and Feng, 1992), and PKA inhibition prior to LTP induction limits the persistence of LTP to roughly $3 \mathrm{~h}$ (Frey et al., 1993). BDNF also facilitates the induction of LTP in hippocampal slices (Korte et al., 1995), and the application of BDNF in the presence of protein synthesis inhibitors is sufficient to transform a short-lasting LTP to a longer-lasting form (Lu et al., 2008), suggesting a role for BDNF in the determination of long-term functional plasticity that is comparable to its necessary and sufficient role in determining LTM persistence (Bekinschtein et al., 2008). Moreover, blockade of BDNF signaling immediately following LTP induction reduced LTP persistence. Specifically, LTP induction in slices generated a transient peak in the phosphorylated form of the TrkB receptor for BDNF; pTrkB levels rose 15 min following induction, peaked at $30 \mathrm{~min}$, and slowly declined to baseline over $2 \mathrm{~h}$ ( $\mathrm{Lu}$ et al., 2011). Preventing TrkB activation with TrkB-IgG at the 30-min peak, but not at 60 min post-induction, inhibited persistent LTP (Kang et al., 1997). The timecourses of these interactions also correspond to those of the early biochemical cascades involved in LTM formation as discussed above.

\subsubsection{Neuronal and synaptic morphology}

Changes in neuronal morphology, such as the growth of new dendritic spines, have been shown to accompany novel experiences (Leggio et al., 2005; Jung and Herms, 2014). Importantly, the stabilization of new dendritic spines underlies at least some LTMs (Yang et al., 2009), indicating that durable modifications of the synaptic weights within neuronal networks mediated by physical spines is a structural mechanism underlying memory persistence (reviewed in Ramiro-Cortés et al., 2014; Sotelo and Dusart, 2014). The specific roles of these morphological elements are further emphasized by the dependence of LTM on intact cytoskeletal dynamics (Lamprecht, 2014). Notably, BDNF and other neurotrophins associated with memory regulation have been strongly implicated in the modification and maintenance of both synaptic efficacy and dendritic morphology (reviewed in McAllister et al., 1995; Castello et al., 2014; Zagrebelsky and Korte, 2014).

\subsubsection{Adult neurogenesis}

Learning and memory in the hippocampus and olfactory bulb also are associated with the incorporation of new adult-born neurons. The proliferation of new neurons ceases prior to adulthood in most brain regions, with the exception of the hippocampus and OB, and possibly the hypothalamus (Cheng, 2013). Hippocampal progenitor cells are produced in the subgranular zone (SGZ) of the hippocampus and migrate a short distance to the granule cell layer of the dentate gyrus (DG); in contrast, OB progenitor cells are produced in the subventricular zone (SVZ) and migrate to the $\mathrm{OB}$ along the rostral migratory stream for 10-14 days before arriving in the $\mathrm{OB}$ and differentiating within the granule cell and glomerular layers (Petreanu and Alvarez-Buylla, 2002). The observation that olfactory learning increases the odorspecific survival of adult-born neurons in $\mathrm{OB}$ (Alonso et al., 2006; Kermen et al., 2010; Sultan et al., 2010) and, conversely, that the selective activation of these adult-born neurons facilitates olfactory performance and memory (Alonso et al., 2012), has led to a broad and well-supported hypothesis that adult neurogenesis underlies LTM in OB as it does in the hippocampus (reviewed in Sahay et al., 2011; Gheusi et al., 2013; Lepousez et al., 2013). However, the observation that this constant integration of new neurons does not result in a progressively increasing total neuron number in the OB (Mouret et al., 2008) suggests that these new neurons may be relatively short-lived, or may replace older neurons, or both, rendering unclear some essential aspects of the role of adult neurogenesis in long-term odor memory within OB.

In the hippocampus, environmental enrichment and experience increase the survival rates of adult-generated neurons within the dentate gyrus (Kee et al., 2007; Tashiro et al., 2007). Moreover, critically, the selective destruction of adult-born neurons that recently had been incorporated into the hippocampal network impaired spatial memory in the Morris water maze task when animals were tested seven days after training (ArrudaCarvalho et al., 2011). This latter result indicates that these newly-incorporated neurons were substantially mediating the new spatial memory; indeed, it has been suggested that adultborn neurons in HPC are employed specifically for new learning (i.e., initial acquisition), as opposed to the expression or reacquisition of memory (Anderson et al., 2011). A similar principle is emerging in the $\mathrm{OB}$, within which the selective ablation of newlyincorporated adult-born neurons following appetitive odor conditioning eliminated animals' memory for that odor (Akers et al., 2011).

Interestingly, some of the signaling mechanisms most strongly associated with LTM formation also appear to be involved in the learning-dependent survival of adult-born neurons. Besides a basic activity-dependence arising from glutamate and GABA receptor activation (Platel et al., 2010; Platel and Bordey, 2011), the survival of adult-born neurons is also enhanced by stimulation with NE (Veyrac et al., 2009; Moreno et al., 2012) or BDNF (Scharfman et al., 2005). For example, infusions of BDNF into the hippocampus, when delivered to adult rats over 2 weeks, increased the number of adult-born granule cells when compared against control animals infused with saline vehicle or bovine serum albumin (Scharfman et al., 2005). In heterozygous BDNF knockout mice, the number of surviving new neurons in the hippocampus did not change (despite increased proliferation in the SGZ); however, adult-born neurons continued to express markers of immature neurons as well as reduced dendritic growth, suggesting that reduced BDNF levels impaired their processes of maturation and differentiation. Other studies have emphasized a role for BDNF in the survival, rather than the proliferation or differentiation, of adult-born neurons (e.g., Sairanen et al., 2005). 


\section{MECHANISMS OF ODOR LEARNING IN THE OB}

Odor learning in the $\mathrm{OB}$ offers rare opportunities to study the molecular and structural mechanisms of learning and memory in concert with well-controlled perceptual and behavioral tasks. During appetitive learning, $\mathrm{OB}$ circuitry integrates information about the statistical properties of the conditioned stimulus, perhaps also incorporating other features of the odor environment, and supports persistent representations of this learning. Insofar as has been studied, the molecular and structural determinants of OB memory appear similar to those described for hippocampal fear conditioning and other memory systems. The particular value of OB-dependent behavioral learning paradigms is that they enable study of these molecular and structural mechanisms in the more complex milieu of cumulative, multi-trial, representational learning, in which the instantiation of LTM is delayed and conditional in nature, and based on information acquired over time. The representational aspect of OB learning further enables study of how learning alters the form, as well as the strength and persistence, of acquired memories.

\subsection{MOLECULAR MECHANISMS IN THE OB}

Intrinsic memory mechanisms within the $\mathrm{OB}$ appear to share common pathways and adhere to similar pharmacologicallyelaborated phases as have been elucidated in IA-based neural plasticity and memory studies. For example, PKA activity in the neonatal rat $\mathrm{OB}$ increases $10 \mathrm{~min}$ after one-trial olfactory appetitive conditioning, and blocking PKA activation in the OB with the competitive inhibitor Rp-cAMPS disrupted odor preference memory when tested 5 or $24 \mathrm{~h}$, but not $3 \mathrm{~h}$, after training. Moreover, exogenous administration of the PKA activator Sp-cAMPs into the OB prior to odor exposure sufficed to induce intermediate $(5 \mathrm{~h})$ and long-term $(24 \mathrm{~h})$ odor preference memory. Higher dosages of Sp-cAMPs into the OB further extended the persistence of this odor preference memory up to $72 \mathrm{~h}$ (Grimes et al., 2012). Odor-reward conditioning, but not odor or reward alone, also induced increased CREB phosphorylation in neonatal $\mathrm{OB}$ mitral cell nuclei $10 \mathrm{~min}$ after training, suggesting that pCREB-related plasticity in mitral cells may be important for the formation of odor LTM (McLean et al., 1999). The MAPK/extracellular signal-related kinase (ERK) pathway also is activated by odor learning in neonates; odor stimulation induced ERK phosphorylation in selective populations of $\mathrm{OB}$ neurons related to the identity of the learned odor (Mirich et al., 2004). Neonatal odor learning, like hippocampal LTM, appears to rely on NMDA receptor activation (Lethbridge et al., 2012) and the increased expression of synaptic AMPA receptors (Cui et al., 2011); notably, the PKA-dependent phosphorylation of AMPA receptor subunit GluA1 rises with a similar timecourse as does the level of CREB phosphorylation in mitral cells, peaking at about $10 \mathrm{~min}$ post-conditioning (Cui et al., 2011). BDNF mRNA levels increase in the $\mathrm{OB}$ and piriform cortex within $2 \mathrm{~h}$ of olfactory fear learning (Jones et al., 2007). To the extent that a substantially common set of essential molecular mechanisms is employed, the important distinctions between one-trial learning and appetitive statistical learning become within which neurons, under what conditions, and to what extent these mechanisms are invoked.
Most studies of olfactory learning and memory that measure the form of the odor memory (typically via generalization gradients) have been performed in adult animals and at STM timescales. There is little research to date on the molecular mechanisms underlying bulbar STM, though there is a substantial literature on the effects of neuromodulators, hormones (Dillon et al., 2013), and other extracellular signaling molecules. Noradrenergic effects within OB, in particular, have been studied in both nonassociative and associative olfactory representational learning studies (reviewed in Linster et al., 2011), which suggest that $\mathrm{NE}$ in the $\mathrm{OB}$ may be necessary for even the simplest forms of odor learning. Notably, a nonspecific infusion of NE into OB suffices to restore the nonassociative learning deficits arising from depletion of cortically-projecting NE fibers (Guérin et al., 2008), though dosage is critical, and bulbar NE levels induced by moderate stress can suppress OB-dependent STM in some contexts (Manella et al., 2013). In neonatal rats, as noted in section 2.2, bulbar NE is heavily released into $\mathrm{OB}$ during odor learning, and exogenous application of $\mathrm{NE}$ into the $\mathrm{OB}$ suffices to induce odor preference learning when paired with an odorant, essentially serving as an unconditioned stimulus as no external source of reward is required (Sullivan et al., 1989; Harley, 2004; Grimes et al., 2012). Activation of the PKA pathway with Sp-cAMPs also acts as an unconditioned stimulus in neonatal $\mathrm{OB}$ in this context (Grimes et al., 2012). There is no evidence, however, that bulbar NE can serve as an unconditioned stimulus for adult odor learning, and even in neonates this property may be epiphenomenal. If NE serves to gate activity-dependent plasticity in $\mathrm{OB}$ circuits, then known properties of neonatal physiology ensure that in neonates this learning will always be strong, always depend on odor-induced activation of OB circuits, and always be appetitive (neonates respond appetitively and can be positively conditioned to even normally-aversive unconditioned stimuli such as electric shocks; Sullivan, 2001). Consequently, simply gating circuit plasticity in the $\mathrm{OB}$ could be expected to directly generate a positive association in neonates. In any event, analogous pairings of odor presentation with bulbar NE infusions in adult mice demonstrate that NE facilitates habituation to presented odors, but does not innately generate odor preferences as it does in neonatal animals (Shea et al., 2008). Of course, other classical neuromodulators, notably acetylcholine acting at muscarinic receptors within $\mathrm{OB}$, also exert effects within OB circuitry on odor learning and STM maintenance (Devore and Linster, 2012; Devore et al., 2012).

BDNF also is clearly implicated in LTM formation for IA learning. While it has been much less thoroughly studied in the olfactory system, BDNF transcription is activated in $\mathrm{OB}$ and piriform cortex after odor conditioning (Jones et al., 2007), and olfactory sensory deprivation reduces $\mathrm{BDNF}$ expression in neonatal $\mathrm{OB}$ (McLean et al., 2001). BDNF and its precursor proBDNF exert distinct physiological effects on $\mathrm{OB}$ neuronal excitability and plasticity (Mast and Fadool, 2012). BDNF heterozygous knockout mice and BDNF(Val66Met) point mutants exhibit reduced activity-dependent secretion of BDNF and behavioral deficits in an OB-dependent task. Both mutants habituate normally to odors but exhibit greatly reduced spontaneous discrimination in the cross-habituation task (Bath et al., 2008), suggesting an impairment in their ability to form specific odor representations. The 
clearest effects of BDNF on the $\mathrm{OB}$, however, are structural in nature, substantially affecting dendritic arborization and adult neurogenesis.

\subsection{STRUCTURAL MECHANISMS IN THE OB}

\subsubsection{Long-term potentiation}

Long-term potentiation has been clearly if sparsely observed in the early olfactory system, notably within piriform cortex and its ascending synapses into OB. NMDA receptor-dependent LTP has been demonstrated at afferent and associative fiber synapses within piriform cortical slices, and coactivation of the two can facilitate a form of associative LTP if local inhibition is suppressed (Kanter and Haberly, 1990, 1993). Piriform pyramidal neuron feedback projections onto OB granule cells also exhibit spike timing-dependent LTP (Gao and Strowbridge, 2009), which may be a particularly powerful computational element given the importance of dynamical, timing-dependent interactions within OB circuitry. Contemporary models of OBpiriform computations have regarded these circuits as a pattern separation/completion network not unlike the dentate gyrus/CA1 circuit of hippocampus, in which piriform association fibers underlie pattern completion (Hasselmo et al., 1992; Barnes et al., 2008) and their feedback projections onto inhibitory granule cells within OB underlie pattern separation (Strowbridge, 2009), within a common recurrent circuit. This rich and structured plasticity requires further experimental and theoretical development, but exemplifies the capacities of the olfactory system as a model for understanding complex memory systems.

\subsubsection{Neuronal and synaptic morphology}

Spine densities in $\mathrm{OB}$ and piriform cortex are affected by odor learning and by learning-associated trophic factors, notably BDNF. In piriform cortex, spine density on pyramidal neurons increased in odor-conditioned rats compared with pseudoconditioned or naïve controls, an effect potentially corresponding to increased synaptic weights in the association fiber network (Knafo et al., 2001). In the neonatal OB, dendritic branching and spine morphology is substantially regulated by BDNF signaling mediated by the TrkB receptor (Matsutani and Yamamoto, 2004; Imamura and Greer, 2009). In adults, BDNF expression in the OB persists (Malkovska et al., 2006), and continues to regulate OB dendritogenesis, at least among parvalbumin-expressing neurons of the external plexiform layer (Berghuis et al., 2006). In combination with the integration of adult-born neurons into the $\mathrm{OB}$ network (below), it is clear that the regulation of dendritic connectivity among $\mathrm{OB}$ neurons is a significant determinant of $\mathrm{OB}$ functional plasticity, and that BDNF is a crucial regulator of the underlying mechanisms.

\subsubsection{Adult neurogenesis}

Adult neurogenesis in the OB has been studied extensively with regard to its effects on, and mediation of, odor learning. The differentiation of adult-born neurons within $\mathrm{OB}$ and its relevance for olfactory perception and odor learning have been extensively studied and reviewed elsewhere (Lazarini and Lledo, 2011; Lepousez et al., 2013; Gheusi et al., 2013). Of particular interest for present purposes, though, is the regulation of these neuronal differentiation processes by signaling molecules and other established mediators of olfactory learning, as well as timing and task dependencies that may suggest points of particular mechanistic importance.

The incorporation of new neurons is most widely associated with olfactory LTM; as described above, the selective ablation of newly differentiated $\mathrm{OB}$ neurons specifically disrupted a longterm odor memory (Akers et al., 2011). However, there also are indications that adult-born neurons may participate in STM processes. Infusions of the antimitotic drug AraC into the lateral ventricle of rats abolished the arrival of new neurons into the $\mathrm{OB}$, while largely sparing hippocampal neurogenesis, and impaired short-term nonassociative memory for odors learned thereafter (Breton-Provencher et al., 2009). Specifically, the absence of new neurons in OB did not affect memory for a habituated odor after $30 \mathrm{~min}$, but 60-, 90-, and 120-min odor memories were disrupted compared with control animals. In contrast, AraC treatment did not affect 24-h or 7-day preference memory for an odorant paired with reward over 4 days. It remains unclear whether this difference depends more on the multi-day spacing of the trials or on the associative nature of the task.

Interestingly, it has been proposed that nonassociative and associative odor learning preferentially activate neurons of different ages within OB (Belnoue et al., 2011). Specifically, nonassociative perceptual learning preferentially activated newly-arrived neurons ( $\sim 2$ weeks old), as measured by c-Fos immunoreactivity, whereas water-rewarded odor discrimination training in a go/no-go task preferentially activated more mature, though still recently generated, interneurons (5-9 weeks of age). This result is consistent with the results described above, in that the OBs of AraC-infused mice in that study were devoid of neurons younger than 3-4 weeks, as required for nonassociative odor learning, but possessed a full complement of neurons in the 5-9 week age range, as were most heavily utilized in the rewarded task. (Also of potential interest is that activation does not necessarily correspond to increased survival; olfactory go/no-go training has been associated with enhancing the survival of 2-4 week old neurons in $\mathrm{OB}$, while increasing apoptosis in 5-week old neurons, and not affecting fully mature interneurons 9 weeks of age or older; Mouret et al., 2008). These results still beg the question, of course, of what factors in these different training paradigms underlie the selective recruitment of different cohorts of new neurons. These results illustrate another advantage of the olfactory system for studies of complex and naturalistic learning, in which task parameters may determine the differential utilization of $\mathrm{OB}$ (and non-OB; Luu et al., 2012) circuit elements for odor-dependent learning.

BDNF signaling is a significant contributor to the survival of new neurons in the OB. BDNF levels are similar in both the site of neurogenesis in the SVZ and in the OB, the target of migration, and regulate both neuronal migration and differentiation (the latter via the MAPK pathway) (Petridis and El Maarouf, 2011). Infusions of BDNF into the lateral ventricle of adult rats significantly increased the generation and/or survival of adult-born neurons in the OB (Zigova et al., 1998; Benraiss et al., 2001); in an analogous in vitro study, BDNF administered to neurons arising from the subependymal zone of rats 
promoted their survival (Kirschenbaum and Goldman, 1995). Mice heterozygous for either the BDNF gene or its TrkB receptor exhibit reduced neuron survival in the $\mathrm{OB}$, as do mice with the Val66Met point mutation in the BDNF gene, which impairs activity-dependent BDNF secretion (Bath et al., 2008); these mutants also exhibited impaired nonassociative odor learning as described above. Neuronal proliferation was not affected by these mutations, suggesting that the effects of BDNF primarily relate to survival and differentiation. The powerful effects of this neurotrophin on olfactory learning and neuronal differentiation, and its association with established learning-associated molecular cascades, render it a strong candidate for study in order to elucidate the complex relationships underlying these representational, statistical learning processes in naturalistic contexts.

\section{IN SUMMARY}

Understanding the neurophysiological basis of natural learning and memory is one of the great challenges of neuroscience. Much of what is known about the cellular mechanisms underlying learning derives from one-trial learning paradigms of inhibitory avoidance (fear conditioning), though research in other plastic neural systems has indicated that they share many, though not all, of the same underlying molecular and structural mechanisms of plasticity. One-trial odor learning studies, which induce plasticity in olfactory bulb, suggest that these cortical circuits also rely on these common mechanisms for plasticity - although bulbar memory also depends on adult neurogenesis, a structural mechanism which it shares only with the hippocampus.

Most natural learning, however, is less categorical than these one-trial paradigms, requiring multiple encounters in order to elucidate relevant stimuli and learn appropriate associations. Appetitive learning in adults, for example, tends to be gradual, conditional, and statistical in nature. This raises new mechanistic questions: how does learning accumulate over multiple trials? How do STM and LTM mechanisms interact over the extended timescales of natural experience? How are the relevant features of the sensory scene identified, selected, and represented? How does learning change the form, or quality, of a sensory representation in response to accumulating information? Developing the olfactory system as a neurophysiological learning and memory model enables engagement with these rich questions.

\section{AUTHOR CONTRIBUTIONS}

Michelle T. Tong and Thomas A. Cleland conceived of and wrote the paper, and designed the figures. Shane T. Peace designed and performed the research featured in Figure 4. Michelle T. Tong designed and performed the research featured in Figure 5.

\section{FUNDING}

This work was supported by NIH/NIDCD grant DC012249 to Thomas A. Cleland.

\section{ACKNOWLEDGMENTS}

The authors would like to thank undergraduate research assistants Alan Leung, Chin Ho Fung, Rahul Krishnan, Dmitriy Migdalovich, Simon Wong, and Zhongming Chen for help with the research conducted in Figures 4, 5. We would also like to thank SiWei Luo (Department of Psychology, Cornell University) for providing valuable discussion and references.

\section{REFERENCES}

Abraham, N. M., Guerin, D., Bhaukaurally, K., and Carleton, A. (2012). Similar odor discrimination behavior in head-restrained and freely moving mice. PLoS ONE 7:e51789. doi: 10.1371/journal.pone.0051789

Abraham, N. M., Vincis, R., Lagier, S., Rodriguez, I., and Carleton, A. (2014). Long term functional plasticity of sensory inputs mediated by olfactory learning. eLife 3:e02109 doi: 10.7554/eLife.02109

Akers, K. G., Arruda-Carvalho, M., and Frankland, P. W. (2011). Ablation of adult-generated olfactory bulb neurons produces retrograde impairment in an associative odor memory task. Soc. Neurosci. Abstr. 834.08.

Alonso, M., Lepousez, G., Wagner, S., Bardy, C., Gabellec, M.-M., Torquet, N., et al. (2012). Activation of adult-born neurons facilitates learning and memory. Nat. Neurosci. 15, 897-904. doi: 10.1038/nn.3108

Alonso, M., Vianna, M. R., Depino, A. M., Mello e Souza, T., Pereira, P., Szapiro, G., et al. (2002). BDNF-triggered events in the rat hippocampus are required for both short- and long-term memory formation. Hippocampus 12, 551-560. doi: 10.1002/hipo.10035

Alonso, M., Viollet, C., Gabellec, M.-M., Meas-Yedid, V., Olivo-Marin, J.-C., and Lledo, P.-M. (2006). Olfactory discrimination learning increases the survival of adult-born neurons in the olfactory bulb. J. Neurosci. 26, 10508-10513. doi: 10.1523/JNEUROSCI.2633-06.2006

Anderson, M. L., Sisti, H. M., Curlik, D. M., and Shors, T. J. (2011). Associative learning increases adult neurogenesis during a critical period. Eur. J. Neurosci. 33, 175-181. doi: 10.1111/j.1460-9568.2010.07486.x

Arruda-Carvalho, M., Sakaguchi, M., Akers, K. G., Josselyn, S. A., and Frankland, P. W. (2011). Posttraining ablation of adult-generated neurons degrades previously acquired memories. J. Neurosci. 31, 15113-15127. doi: 10.1523/JNEUROSCI.3432-11.2011

Barnes, D. C., Hofacer, R. D., Zaman, A. R., Rennaker, R. L., and Wilson, D. A. (2008). Olfactory perceptual stability and discrimination. Nat. Neurosci. 11, 1378-1380. doi: 10.1038/nn.2217

Bath, K. G., Mandairon, N., Jing, D., Rajagopal, R., Kapoor, R., Chen, Z.-Y., et al. (2008). Variant brain-derived neurotrophic factor (Val66Met) alters adult olfactory bulb neurogenesis and spontaneous olfactory discrimination. J. Neurosci. 28, 2383-2393. doi: 10.1523/JNEUROSCI.4387-07.2008

Bekinschtein, P., Cammarota, M., Igaz, L. M., Bevilaqua, L. R., Izquierdo, I., and Medina, J. H. (2007). Persistence of long-term memory storage requires a late protein synthesis- and BDNF-dependent phase in the hippocampus. Neuron 53 , 261-277. doi: 10.1016/j.neuron.2006.11.025

Bekinschtein, P., Cammarota, M., Katche, C., Slipczuk, L., Rossato, J. I., Goldin, A., et al. (2008). BDNF is essential to promote persistence of long-term memory storage. Proc. Natl. Acad. Sci. U.S.A. 105, 2711-2716. doi: 10.1073/pnas.07118 63105

Belnoue, L., Grosjean, N., Abrous, D. N., and Koehl, M. (2011). A critical time window for the recruitment of bulbar newborn neurons by olfactory discrimination learning. J. Neurosci. 31, 1010-1016. doi: 10.1523/JNEUROSCI.3941-10.2011

Benraiss, A., Chmielnicki, E., Lerner, K., Roh, D., and Goldman, S. A. (2001). Adenoviral brain-derived neurotrophic factor induces both neostriatal and olfactory neuronal recruitment from endogenous progenitor cells in the adult forebrain. J. Neurosci. 21, 6718-6731.

Berdel, B., Moryś, J., and Maciejewska, B. (1997). Neuronal changes in the basolateral complex during development of the amygdala of the rat. Int. J. Dev. Neurosci. 15, 755-765. doi: 10.1016/S0736-5748(97)00022-1

Berghuis, P., Agerman, K., Dobszay, M. B., Minichiello, L., Harkany, T., and Ernfors, P. (2006). Brain-derived neurotrophic factor selectively regulates dendritogenesis of parvalbumin-containing interneurons in the main olfactory bulb through the PLC $\gamma$ pathway. J. Neurobiol. 66, 1437-1451. doi: 10.1002/neu.20319

Bernabeu, R., Bevilaqua, L., Ardenghi, P., Bromberg, E., Schmitz, P., Bianchin, M., et al. (1997a). Involvement of hippocampal cAMP/cAMP-dependent protein kinase signaling pathways in a late memory consolidation phase of aversively motivated learning in rats. Proc. Natl. Acad. Sci. U.S.A. 94, 7041-7046.

Bernabeu, R., Cammarota, M., Izquierdo, I., and Medina, J. H. (1997b). Involvement of hippocampal AMPA glutamate receptor changes and the cAMP/protein kinase A/CREB-P signalling pathway in memory consolidation of an avoidance task in rats. Brazil. J. Med. Biol. Res. 30, 961-965. 
Bernabeu, R., Schmitz, P., Faillace, M. P., Izquierdo, I., and Medina, J. H. (1996). Hippocampal cGMP and cAMP are differentially involved in memory processing of inhibitory avoidance learning. Neuroreport 7, 585-588.

Bernabeu, R., Schroder, N., Quevedo, J., Izquierdo, I., and Medina, J. H. $(1997 \mathrm{c})$. Further evidence for the involvement of a hippocampal cGMP/cGMPdependent protein kinase cascade in memory consolidation. Neuroreport 8, 2221-2224.

Bevilaqua, L., Ardenghi, P., Schroder, N., Bromberg, E., Schmitz, P., Schaeffer, E., et al. (1997). Drugs acting upon the cyclic adenosine monophosphate/protein kinase A signalling pathway modulate memory consolidation when given late after training into rat hippocampus but not amygdala. Behav. Pharmacol. 8, 331-338.

Bieszczad, K. M., and Weinberger, N. M. (2010). Representational gain in cortical area underlies increase of memory strength. Proc. Natl. Acad. Sci. U.S.A. 107, 3793-3798. doi: 10.1073/pnas.1000159107

Bliss, T. V., and Collingridge, G. L. (1993). A synaptic model of memory: long-term potentiation in the hippocampus. Nature 361, 31-39. doi: 10.1038/361031a0

Bliss, T. V., and Lømo, T. (1973). Long-lasting potentiation of synaptic transmission in the dentate area of the anaesthetized rabbit following stimulation of the perforant path. J. Physiol. 232, 331-356.

Blum, A. L., Li, W., Cressy, M., and Dubnau, J. (2009). Short- and long-term memory in Drosophila require cAMP signaling in distinct neuron types. Curr. Biol. 19, 1341-1350. doi: 10.1016/j.cub.2009.07.016

Bourtchuladze, R., Frenguelli, B., Blendy, J., Cioffi, D., Schütz, G., and Silva, A. J. (1994). Deficient long-term memory in mice with a targeted mutation of the cAMP-responsive element-binding protein. Cell 79, 59-68. doi: 10.1016/00928674(94)90400-6

Breton-Provencher, V., Lemasson, M., Peralta, M. R., and Saghatelyan, A. (2009). Interneurons produced in adulthood are required for the normal functioning of the olfactory bulb network and for the execution of selected olfactory behaviors. J. Neurosci. 29, 15245-15257. doi: 10.1523/JNEUROSCI.3606-09.2009

Cammarota, M., Paratcha, G., Levi de Stein, M., Bernabeu, R., Izquierdo, I., and Medina, J. H. (1997). B-50/GAP-43 phosphorylation and PKC activity are increased in rat hippocampal synaptosomal membranes after an inhibitory avoidance training. Neurochem. Res. 22, 499-505.

Canal, C. E., Chang, Q., and Gold, P. E. (2008). Intra-amygdala injections of CREB antisense impair inhibitory avoidance memory: role of norepinephrine and acetylcholine. Learn. Mem. 15, 677-686. doi: 10.1101/lm.904308

Castello, N. A., Nguyen, M. H., Tran, J. D., Cheng, D., Green, K. N., and LaFerla, F. M. (2014). 7,8-dihydroxyflavone, a small molecule TrkB agonist, improves spatial memory and increases thin spine density in a mouse model of Alzheimer disease-like neuronal loss. PLoS ONE 9:e91453. doi: 10.1371/journal.pone.0091453

Chaudhury, D., Manella, L., Arellanos, A., Escanilla, O., Cleland, T. A., and Linster, C. (2010). Olfactory bulb habituation to odor stimuli. Behav. Neurosci. 124, 490-499. doi: 10.1037/a0020293

Chen, C. F., Barnes, D. C., and Wilson, D. A. (2011). Generalized vs. stimulus-specific learned fear differentially modifies stimulus encoding in primary sensory cortex of awake rats. J. Neurophysiol. 106, 3136-3144. doi: 10.1152/jn.00721.2011

Chen, D. Y., Bambah-Mukku, D., Pollonini, G., and Alberini, C. M. (2012). Glucocorticoid receptors recruit the CaMKII $\alpha$-BDNF-CREB pathways to mediate memory consolidation. Nat. Neurosci. 15, 1707-1714. doi: 10.1038/ nn. 3266

Cheng, M. F. (2013). Hypothalamic neurogenesis in the adult brain. Front. Neuroendocrinol. 34, 167-178. doi: 10.1016/j.yfrne.2013.05.001

Cleland, T. A. (2008). "The construction of olfactory representations," in Mechanisms of Information Processing in the Brain: Encoding of Information in Neural Populations, eds C. Holscher and M. Munk (Cambridge, UK: Cambridge University Press), 247-280.

Cleland, T. A. (2014). "Construction of odor representations by olfactory bulb microcircuits," in Progress in Brain Research: Odor Memory and Perception, eds E. Barkai and D. Wilson (New York, NY: Elsevier), 177-203.

Cleland, T. A., Chen, S. Y., Hozer, K. W., Ukatu, H. N., Wong, K. J., and Zheng, F. (2012). Sequential mechanisms underlying concentration invariance in biological olfaction. Front. Neuroeng. 4:21. doi: 10.3389/fneng.2011.00021.

Cleland, T. A., Morse, A., Yue, E. L., and Linster, C. (2002). Behavioral models of odor similarity. Behav. Neurosci. 116, 222-231. doi: 10.1037/07357044.116.2.222
Cleland, T. A., Narla, V. A., and Boudadi, K. (2009). Multiple learning parameters differentially regulate olfactory generalization. Behav. Neurosci. 123, 26-35. doi: 10.1037/a0013991

Cui, W., Darby-King, A., Grimes, M. T., Howland, J. G., Wang, Y. T., McLean, J. H., et al. (2011). Odor preference learning and memory modify GluAl phosphorylation and GluAl distribution in the neonate rat olfactory bulb: testing the AMPA receptor hypothesis in an appetitive learning model. Learn. Mem. 18, 283-291. doi: 10.1101/lm.1987711

Danysz, W., Zajaczkowski, W., and Parsons, C. G. (1995). Modulation of learning processes by ionotropic glutamate receptor ligands. Behav. Pharmacol. 6, 455-474.

Davis, H. P., and Squire, L. R. (1984). Protein synthesis and memory: a review. Psychol. Bull. 96, 518-559.

de Almeida, L., Idiart, M., and Linster, C. (2013). A model of cholinergic modulation in olfactory bulb and piriform cortex. J. Neurophysiol. 109, 1360-1377.

Devore, S., and Linster, C. (2012). Noradrenergic and cholinergic modulation of olfactory bulb sensory processing. Front. Behav. Neurosci. 6:52. doi: 10.3389/fnbeh.2012.00052

Devore, S., Manella, L. C., and Linster, C. (2012). Blocking muscarinic receptors in the olfactory bulb impairs performance on an olfactory short-term memory task. Front. Behav. Neurosci. 6:59. doi: 10.3389/fnbeh.2012.00059

DeZazzo, J., and Tully, T. (1995). Dissection of memory formation: from behavioral pharmacology to molecular genetics. Trends Neurosci. 18, 212-218. doi: 10.1016/0166-2236(95)93905-D

Dillon, T. S., Fox, L. C., Han, C., and Linster, C. (2013). 17 $\beta$-estradiol enhances memory duration in the main olfactory bulb in CD-1 mice. Behav. Neurosci. 127, 923-931. doi: 10.1037/a0034839

Eichenbaum, H. (1998). Using olfaction to study memory. Ann. N.Y. Acad. Sci. 855, 657-669. doi: 10.1111/j.1749-6632.1998.tb10642.x

Eichenbaum, H., Schoenbaum, G., Young, B., and Bunsey, M. (1996). Functional organization of the hippocampal memory system. Proc. Natl. Acad. Sci. U.S.A. 93, 13500-13507. doi: 10.1073/pnas.93.24.13500

Escanilla, O., Alperin, S., Youssef, M., Ennis, M., and Linster, C. (2012). Noradrenergic but not cholinergic modulation of olfactory bulb during processing of near threshold concentration stimuli. Behav. Neurosci. 126, 720-728. doi: $10.1037 / \mathrm{a} 0030006$

Escanilla, O., Arrellanos, A., Karnow, A., Ennis, M., and Linster, C. (2010). Noradrenergic modulation of behavioral odor detection and discrimination thresholds in the olfactory bulb. Eur. J. Neurosci. 32, 458-468. doi: 10.1111/j.1460-9568.2010.07297.x

Fernandez, P. C., Locatelli, F. F., Person-Rennell, N., Deleo, G., and Smith, B. H. (2009). Associative conditioning tunes transient dynamics of early olfactory processing. J. Neurosci. 29, 10191-10202. doi: 10.1523/JNEUROSCI.187409.2009

Freedman, K. G., Radhakrishna, S., Escanilla, O., and Linster, C. (2013). Duration and specificity of olfactory nonassociative memory. Chem. Sens. 38, 369-375. doi: 10.1093/chemse/bjt010

Frey, U., Huang, Y. Y., and Kandel, E. R. (1993). Effects of cAMP simulate a late stage of LTP in hippocampal CA1 neurons. Science 260, 1661-1664. doi: $10.1126 /$ science. 8389057

Frey, U., Krug, M., Reymann, K. G., and Matthies, H. (1988). Anisomycin, an inhibitor of protein synthesis, blocks late phases of LTP phenomena in the hippocampal CA1 region in vitro. Brain Res. 452, 57-65. doi: 10.1016/00068993(88)90008-X

Frey, U., Schollmeier, K., Reymann, K., and Seidenbecher, T. (1995). Asymptotic hippocampal long-term potentiation in rats does not preclude additional potentiation at later phases. Neuroscience 67, 799-807. doi: 10.1016/03064522(95)00117-2

Gao, Y., and Strowbridge, B. W. (2009). Long-term plasticity of excitatory inputs to granule cells in the rat olfactory bulb. Nat. Neurosci. 12, 731-733. doi: 10.1038/nn.2319

Gheusi, G., Lepousez, G., and Lledo, P.-M. (2013). "Adult-born neurons in the olfactory bulb: integration and functional consequences," in Neurogenesis and Neural Plasticity, eds C. Belzung and P. Wigmore (Berlin: Springer), 49-72.

Grimes, M. T., Harley, C. W., Darby-King, A., and McLean, J. H. (2012). PKA increases in the olfactory bulb act as unconditioned stimuli and provide evidence for parallel memory systems: pairing odor with increased PKA creates intermediate- and long-term, but not short-term, memories. Learn. Mem. 19, 107-115. doi: 10.1101/lm.024489.111 
Grimes, M. T., Smith, M., Li, X., Darby-King, A., Harley, C. W., and McLean, J. H. (2011). Mammalian intermediate-term memory: New findings in neonate rat. Neurobiol. Learn. Mem. 95, 385-391. doi: 10.1016/j.nlm.2011.01.012

Guérin, D., Peace, S. T., Didier, A., Linster, C., and Cleland, T. A. (2008). Noradrenergic neuromodulation in the olfactory bulb modulates odor habituation and spontaneous discrimination. Behav. Neurosci. 122, 816-826. doi: $10.1037 / \mathrm{a} 0012522$

Guzowski, J. F., and McGaugh, J. L. (1997). Antisense oligodeoxynucleotidemediated disruption of hippocampal cAMP response element binding protein levels impairs consolidation of memory for water maze training. Proc. Natl. Acad. Sci. U.S.A. 94, 2693-2698. doi: 10.1073/pnas.94.6.2693

Harley, C. W. (2004). Norepinephrine and dopamine as learning signals. Neural Plast. 11, 191-204.

Hasselmo, M. E., Anderson, B. P., and Bower, J. M. (1992). Cholinergic modulation of cortical associative memory function. J. Neurophysiol. 67, 1230-1246. doi: 10.1155/NP.2004.191

Imamura, F., and Greer, C. A. (2009). Dendritic branching of olfactory bulb mitral and tufted cells: regulation by TrkB. PLoS ONE 4:e6729. doi: 10.1371/journal.pone.0006729

Izquierdo, I. (1993). Long-term potentiation and the mechanisms of memory. Drug Dev. Res. 30, 1-17. doi: 10.1002/ddr.430300102

Izquierdo, I., Barros, D. M., Mello e Souza, T., de Souza, M. M., Izquierdo, L. A., and Medina, J. H. (1998). Mechanisms for memory types differ. Nature 393, 635-636. doi: 10.1038/31371

Izquierdo, I., Da Cunha, C., Rosat, R., Jerusalinsky, D., Ferreira, M., and Medina, J. H. (1992). Neurotransmitter receptors involved in post-training memory processing by the amygdala, medial septum and hippocampus of the rat. Behav. Neural Biol. 58, 16-26. doi: 10.1016/0163-1047(92)90847-W

Izquierdo, I., Medina, J. H., Vianna, M. R., Izquierdo, L. A., and Barros, D. M. (1999). Separate mechanisms for short-and long-term memory. Behav. Brain Res. 103, 1-11. doi: 10.1016/S0166-4328(99)00036-4

Izquierdo, L. (2000). Short- and long-term memory are differentially affected by metabolic inhibitors given into hippocampus and entorhinal cortex. Neurobiol. Learn. Mem. 73, 141-149. doi: 10.1006/nlme.1999.3925

Izquierdo, L., Schroder, N., Ardenghi, P., Quevedo, J., Bevilaqua, L., Netto, C., et al. (1997). Systemic administration of ACTH or vasopressin reverses the amnestic effect of posttraining beta-endorphin or electroconvulsive shock but not that of intrahippocampal infusion of protein kinase inhibitors. Learn. Mem. 68, 197-202. doi: 10.1006/nlme.1997.3794

Jerusalinsky, D., Ferreira, M. B., Walz, R., Da Silva, R. C., Bianchin, M., Ruschel, A. C., et al. (1992). Amnesia by post-training infusion of glutamate receptor antagonists into the amygdala, hippocampus and entorhinal cortex. Behav. Neural Biol. 58, 76-80. doi: 10.1016/0163-1047(92)90982-A

Jerusalinsky, D., Quillfeldt, J. H., Walz, R., Da Silva, R., Medina, J. H., and Izquierdo, I. (1994). Post-training intrahippocampal infusion of protein kinase C inhibitors causes amnesia in rats. Behav. Neural Biol. 61, 107-109. doi: 10.1016/S0163-1047(05)80063-9

Jones, S. V., Stanek-Rattiner, L., Davis, M., and Ressler, K. J. (2007). Differential regional expression of brain-derived neurotrophic factor following olfactory fear learning. Learn. Mem. 14, 816-820. doi: 10.1101/lm.781507

Jung, C. K., and Herms, J. (2014). Structural dynamics of dendritic spines are influenced by an environmental enrichment: an in vivo imaging study. Cereb. Cortex 24, 377-384. doi: 10.1093/cercor/bhs317

Kang, H., Welcher, A. A., Shelton, D., and Schuman, E. M. (1997). Neurotrophins and time: different roles for TrkB signaling in hippocampal long-term potentiation. Neuron 19, 653-664. doi: 10.1016/S0896-6273(00)80378-5

Kanter, E. D., and Haberly, L. B. (1993). Associative long-term potentiation in piriform cortex slices requires GABAA blockade. J. Neurosci. 13, 2477-2482.

Kanter, E. D., and Haberly, L. B. (1990). NMDA-dependent induction of long-term potentiation in afferent and association fiber systems of piriform cortex in vitro. Brain Res. 525, 175-179. doi: 10.1016/0006-8993(90) 91337-G

Kee, N., Teixeira, C. M., Wang, A. H., and Frankland, P. W. (2007). Preferential incorporation of adult-generated granule cells into spatial memory networks in the dentate gyrus. Nat. Neurosci. 10, 355-362. doi: 10.1038/nn1847

Kermen, F., Sultan, S., Sacquet, J., Mandairon, N., and Didier, A. (2010). Consolidation of an olfactory memory trace in the olfactory bulb is required for learning-induced survival of adult-born neurons and long-term memory. PLoS ONE 5:e12118. doi: 10.1371/journal.pone.0012118
Kirschenbaum, B., and Goldman, S. A. (1995). Brain-derived neurotrophic factor promotes the survival of neurons arising from the adult rat forebrain subependymal zone. Proc. Natl. Acad. Sci. U.S.A. 92, 210-214. doi: 10.1073/pnas.92.1.210

Knafo, S., Grossman, Y., Barkai, E., and Benshalom, G. (2001). Olfactory learning is associated with increased spine density along apical dendrites of pyramidal neurons in the rat piriform cortex. Eur. J. Neurosci. 13, 633-638. doi: 10.1046/j.1460-9568.2001.01422.x

Korte, M., Carroll, P., Wolf, E., Brem, G., Thoenen, H., and Bonhoeffer, T. (1995). Hippocampal long-term potentiation is impaired in mice lacking brainderived neurotrophic factor. Proc. Natl. Acad. Sci. U.S.A. 92, 8856-8860. doi 10.1073/pnas.92.19.8856

Krug, M., Lössner, B., and Ott, T. (1984). Anisomycin blocks the late phase of longterm potentiation in the dentate gyrus of freely moving rats. Brain Res. Bull. 13, 39-42. doi: 10.1016/0361-9230(84)90005-4

Lamprecht, R. (2014). The actin cytoskeleton in memory formation. Prog. Neurobiol. 117C, 1-19. doi: 10.1016/j.pneurobio.2014.02.001

Law, L. M., and Smith, D. M. (2012). The anterior thalamus is critical for overcoming interference in a context-dependent odor discrimination task. Behav. Neurosci. 126, 710-719. doi: 10.1037/a0029698

Lazarini, F., and Lledo, P.-M. (2011). Is adult neurogenesis essential for olfaction? Trends Neurosci. 34, 20-30. doi: 10.1016/j.tins.2010.09.006

Leggio, M. G., Mandolesi, L., Federico, F., Spirito, F., Ricci, B., Gelfo, F., et al. (2005). Environmental enrichment promotes improved spatial abilities and enhanced dendritic growth in the rat. Behav. Brain Res. 163, 78-90. doi: 10.1016/j.bbr.2005.04.009

Lepousez, G., Valley, M. T., and Lledo, P.-M. (2013). The impact of adult neurogenesis on olfactory bulb circuits and computations. Annu. Rev. Physiol. 75, 339-363. doi: 10.1146/annurev-physiol-030212-183731

Lethbridge, R., Hou, Q., Harley, C. W., and Yuan, Q. (2012). Olfactory bulb glomerular NMDA receptors mediate olfactory nerve potentiation and odor preference learning in the neonate rat. PLoS ONE 7:e35024. doi: 10.1371/journal.pone. 0035024

Li, G., and Cleland, T. A. (2013). A two-layer biophysical model of cholinergic neuromodulation in olfactory bulb. J. Neurosci. 33, 3037-3058. doi: 10.1523/JNEUROSCI.2831-12.2013

Linster, C., and Cleland, T. A. (2010). Decorrelation of odor representations via spike timing-dependent plasticity. Front. Comput. Neurosci. 4:157. doi: 10.3389/fncom.2010.00157

Linster, C., Nai, Q., and Ennis, M. (2011). Nonlinear effects of noradrenergic modulation of olfactory bulb function in adult rodents. J. Neurosci. 105, 1432-1443. doi: 10.1152/jn.00960.2010

Lledo, P.-M., Alonso, M., and Grubb, M. S. (2006). Adult neurogenesis and functional plasticity in neuronal circuits. Nat. Rev. Neurosci. 7, 179-193. doi: 10.1038/nrn1867

Lu, Y., Christian, K., and Lu, B. (2008). BDNF: a key regulator for protein synthesisdependent LTP and long-term memory? Neurobiol. Learn. Mem. 89, 312-323. doi: 10.1016/j.nlm.2007.08.018

Lu, Y., Ji, Y., Ganesan, S., Schloesser, R., Martinowich, K., Sun, M., et al. (2011). TrkB as a potential synaptic and behavioral tag. J. Neurosci. 31, 11762-11771. doi: 10.1523/JNEUROSCI.2707-11.2011

Luu, P., Sill, O. C., Gao, L., Becker, S., Wojtowicz, J. M., and Smith, D. M. (2012). The role of adult hippocampal neurogenesis in reducing interference. Behav. Neurosci. 126, 381-391. doi: 10.1037/a0028252

Malinow, R., Schulman, H., and Tsien, R. W. (1989). Inhibition of postsynaptic PKC or CaMKII blocks induction but not expression of LTP. Science 245, 862-866. doi: 10.1126/science. 2549638

Malkovska, I., Kernie, S. G., and Parada, L. F. (2006). Differential expression of the four untranslated BDNF exons in the adult mouse brain. J. Neurosci. Res. 83, 211-221. doi: 10.1002/jnr.20728

Mandairon, N., Ferretti, C. J., Stack, C. M., Rubin, D. B., Cleland, T. A., and Linster, C. (2006). Cholinergic modulation in the olfactory bulb influences spontaneous olfactory discrimination in adult rats. Eur. J. Neurosci. 24, 3234-3244. doi: 10.1111/j.1460-9568.2006.05212.x

Mandairon, N., Peace, S., Karnow, A., Kim, J., Ennis, M., and Linster, C. (2008). Noradrenergic modulation in the olfactory bulb influences spontaneous and reward-motivated discrimination, but not the formation of habituation memory. Eur. J. Neurosci. 27, 1210-1219. doi: 10.1111/j.1460-9568.2008. 06101.x 
Manella, L. C., Alperin, S., and Linster, C. (2013). Stressors impair odor recognition memory via an olfactory bulb-dependent noradrenergic mechanism. Front. Integr. Neurosci. 7:97. doi: 10.3389/fnint.2013. 00097

Mast, T. G., and Fadool, D. A. (2012). Mature and precursor brain-derived neurotrophic factor have individual roles in the mouse olfactory bulb. PLoS ONE 7:e31978. doi: 10.1371/journal.pone.0031978

Matsutani, S., and Yamamoto, N. (2004). Brain-derived neurotrophic factor induces rapid morphological changes in dendritic spines of olfactory bulb granule cells in cultured slices through the modulation of glutamatergic signaling. Neuroscience 123, 695-702. doi: 10.1016/j.neuroscience.2003.10.030

McAllister, K. A., Lo, D. C., and Katz, L. C. (1995). Neurotrophins regulate dendritic growth in developing visual cortex. Neuron 15, 791-803.

McLean, J. H., Darby-King, A., and Bonnell, W. S. (2001). Neonatal olfactory sensory deprivation decreases BDNF in the olfactory bulb of the rat. Dev. Brain Res. 128, 17-24. doi: 10.1016/S0165-3806(01)00144-4

McLean, J. H., Darby-King, A., and Harley, C. W. (2005). Potentiation and prolongation of long-term odor memory in neonate rats using a phosphodiesterase inhibitor. Neuroscience 135, 329-334. doi: 10.1016/j.neuroscience.2005.06.029

McLean, J. H., and Harley, C. W. (2004). Olfactory learning in the rat pup: a model that may permit visualization of a mammalian memory trace. Neuroreport 15 , 1691-1697. doi: 10.1097/01.wnr.0000134988.51310.c3

McLean, J. H., Harley, C. W., Darby-King, A., and Yuan, Q. (1999). pCREB in the neonate rat olfactory bulb is selectively and transiently increased by odor preference-conditioned training. Learn. Mem. 6, 608-618. doi: 10.1101/lm.6.6.608

McNamara, A. M., Magidson, P. D., Linster, C., Wilson, D. A., and Cleland, T. A. (2008). Distinct neural mechanisms mediate olfactory memory formation at different timescales. Learn. Mem. 15, 117-125. doi: 10.1101/lm.785608

Menzel, R., Manz, G., Menzel, R., and Greggers, U. (2001). Massed and spaced learning in honeybees: the role of CS, US, the intertrial interval, and the test interval. Learn. Mem. 8, 198-208. doi: 10.1101/lm.40001

Migliore, M., and Shepherd, G. M. (2002). Emerging rules for the distributions of active dendritic conductances. Nat. Rev. Neurosci. 3, 362-370. doi: 10.1038/nrn810

Mirich, J. M., Illig, K. R., and Brunjes, P. C. (2004). Experience-dependent activation of extracellular signal-related kinase (ERK) in the olfactory bulb. J. Comp. Neurol. 479, 234-241. doi: 10.1002/cne.20325

Miyamoto, E. (2006). Molecular mechanism of neuronal plasticity: induction and maintenance of long-term potentiation in the hippocampus. J. Pharmacol. Sci. 100, 433-442. doi: 10.1254/jphs.CPJ06007X

Mizuno, M., Yamada, K., Maekawa, N., Saito, K., Seishima, M., and Nabeshima, T. (2002). CREB phosphorylation as a molecular marker of memory processing in the hippocampus for spatial learning. Behav. Brain Res. 133, 135-141. doi: 10.1016/S0166-4328(01)00470-3

Mizuno, M., Yamada, K., Olariu, A., Nawa, H., and Nabeshima, T. (2000). Involvement of brain-derived neurotrophic factor in spatial memory formation and maintenance in a radial arm maze test in rats. J. Neurosci. 20, 7116-7121.

Moreno, M., Bath, K., Kuczewski, N., Sacquet, J., Didier, A., and Mandairon, N. (2012). Action of the noradrenergic system on adult-born cells is required for olfactory learning in mice. J. Neurosci. 32, 3748-3758. doi: 10.1523/JNEUROSCI.6335-11.2012

Moreno, M. M., Linster, C., Escanilla, O., Sacquet, J., Didier, A., and Mandairon, N. (2009). Olfactory perceptual learning requires adult neurogenesis. Proc. Natl. Acad. Sci. U.S.A. 106, 17980-17985. doi: 10.1073/pnas.0907063106

Moriceau, S., and Sullivan, R. M. (2005). Neurobiology of infant attachment. Dev. Psychobiol. 47, 230-242. doi: 10.1002/dev.20093

Mouret, A., Gheusi, G., Gabellec, M. M., de Chaumont, F., Olivo-Marin, J. C., and Lledo, P. M. (2008). Learning and survival of newly generated neurons: when time matters. J. Neurosci. 28, 11511-11516. doi: 10.1523/JNEUROSCI.295408.2008

Peters, G. J., David, C. N., Marcus, M. D., and Smith, D. M. (2013). The medial prefrontal cortex is critical for memory retrieval and resolving interference. Learn. Mem. 20, 201-209. doi: 10.1101/lm.029249.112

Petreanu, L., and Alvarez-Buylla, A. (2002). Maturation and death of adultborn olfactory bulb granule neurons: role of olfaction. J. Neurosci. 22, 6106-6113.

Petridis, A. K., and El Maarouf, A. (2011). Brain-derived neurotrophic factor levels influence the balance of migration and differentiation of subventricular zone cells, but not guidance to the olfactory bulb. J. Clin. Neurosci. 18, 265-270. doi: 10.1016/j.jocn.2010.06.021

Platel, J.-C., and Bordey, A. (2011). "Control of adult-born neuron production by converging GABA and glutamate signals," in Neurogenesis in the Adult Brain I: Neurobiology, eds T. Seki, K. Sawamoto, J. M. Parent, and A. Alvarez-Buylla (Berlin: Springer), 395-406. doi: 10.1007/978-4-43153933-9_17

Platel, J.-C., Dave, K. A., Gordon, V., Lacar, B., Rubio, M. E., and Bordey, A. (2010). NMDA receptors activated by subventricular zone astrocytic glutamate are critical for neuroblast survival prior to entering a synaptic network. Neuron 65, 859-872. doi: 10.1016/j.neuron.2010.03.009

Qiu, Q., Scott, A., Scheerer, H., Sapkota, N., Lee, D. K., Ma, L., et al. (2014). Automated analyses of innate olfactory behaviors in rodents. PLoS ONE 9:e93468. doi: 10.1371/journal.pone.0093468

Ramiro-Cortés, Y., Hobbiss, A. F., and Israely, I. (2014). Synaptic competition in structural plasticity and cognitive function. Phil. Trans. R. Soc. B Biol. Sci. 369:20130157. doi: 10.1098/rstb.2013.0157

Rinberg, D., Koulakov, A., and Gelperin, A. (2006). Speed-accuracy tradeoff in olfaction. Neuron 51, 351-358. doi: 10.1016/j.neuron.2006.07.013

Sahay, A., Wilson, D. A., and Hen, R. (2011). Pattern separation: a common function for new neurons in hippocampus and olfactory bulb. Neuron 70, 582-588. doi: 10.1016/j.neuron.2011.05.012

Sairanen, M., Lucas, G., Ernfors, P., Castrén, M., and Castrén, E. (2005). Brainderived neurotrophic factor and antidepressant drugs have different but coordinated effects on neuronal turnover, proliferation, and survival in the adult dentate gyrus. J. Neurosci. 25, 1089-1094. doi: 10.1523/JNEUROSCI.374104.2005

Sanhueza, J., and Lisman, J. (2013). The CaMKII/NMDAR complex as a molecular memory. Mol. Brain 6:10. doi: 10.1186/1756-6606-6-10

Scharfman, H., Goodman, J., Macleod, A., Phani, S., Antonelli, C., and Croll, S. (2005). Increased neurogenesis and the ectopic granule cells after intrahippocampal BDNF infusion in adult rats. Exp. Neurol. 192, 348-356. doi: 10.1016/j.expneurol.2004.11.016

Schellinck, H. M., Forestell, C. A., and LoLordo, V. M. (2001). A simple and reliable test of olfactory learning and memory in mice. Chem. Sens. 26, 663-672. doi: 10.1093/chemse/26.6.663

Shea, S. D., Katz, L. C., and Mooney, R. (2008). Noradrenergic induction of odor-specific neural habituation and olfactory memories. J. Neurosci. 28, 10711-10719. doi: 10.1523/JNEUROSCI.3853-08.2008

Shepard, R. N. (1987). Toward a universal law of generalization for psychological science. Science 237, 1317-1323. doi: 10.1126/science.3629243

Sotelo, C., and Dusart, I. (2014). "Structural plasticity in adult nervous system: an historic perspective," in Endogenous Stem Cell-Based Brain Remodeling in Mammals, eds M.-P. Junier and S. G. Kernie (New York, NY: Springer), 5-41.

Strowbridge, B. W. (2009). Role of cortical feedback in regulating inhibitory microcircuits. Ann. N.Y. Acad. Sci. 1170, 270-274. doi: 10.1111/j.17496632.2009.04018.x

Sullivan, R. M. (2001). Unique characteristics of neonatal classical conditioning: the role of the amygdala and locus coeruleus. Integr. Physiol. Behav. Sci. 36, 293-307. doi: 10.1007/BF02688797

Sullivan, R. M. (2003). Developing a sense of safety: the neurobiology of neonatal attachment. Ann. N.Y. Acad. Sci. 1008, 122-131. doi: 10.1196/annals.130.013

Sullivan, R. M., Landers, M., Yeaman, B., and Wilson, D. A. (2000). Neurophysiology: good memories of bad events in infancy. Nature 407, 38-39. doi: $10.1038 / 35024156$

Sullivan, R. M., McGaugh, J. L., and Leon, M. (1991). Norepinephrine-induced plasticity and one-trial olfactory learning in neonatal rats. Brain Res. Dev. Brain Res. 60, 219-228. doi: 10.1016/0165-3806(91)90050-S

Sullivan, R. M., Wilson, D. A., and Leon, M. (1989). Norepinephrine and learninginduced plasticity in infant rat olfactory system. J. Neurosci. 9, 3998-4006.

Sultan, S., Mandairon, N., Kermen, F., Garcia, S., Sacquet, J., and Didier, A. (2010). Learning-dependent neurogenesis in the olfactory bulb determines long-term olfactory memory. FASEB J. 24, 2355-2363. doi: 10.1096/fj.09-151456

Sutton, M. A., Bagnall, M. W., Sharma, S. K., Shobe, J., and Carew, T. J. (2004). Intermediate-term memory for site-specific sensitization in Aplysia is maintained by persistent activation of protein kinase C. J. Neurosci. 24, 3600-3609. doi: 10.1523/JNEUROSCI.1134-03.2004

Sutton, M. A., Ide, J., Masters, S. E., and Carew, T. J. (2002). Interaction between amount and pattern of training in the induction of intermediate- 
and long-term memory for sensitization in Aplysia. Learn. Mem. 9, 29-40. doi: 10.1101/lm.44802

Sutton, M. A., Masters, S. E., Bagnall, M. W., and Carew, T. J. (2001). Molecular mechanisms underlying a unique intermediate phase of memory in Aplysia. Neuron 31, 143-154. doi: 10.1016/S0896-6273(01)00342-7

Tashiro, A., Makino, H., and Gage, F. H. (2007). Experience-specific functional modification of the dentate gyrus through adult neurogenesis: a critical period during an immature stage. J. Neurosci. 27, 3252-3259. doi: 10.1523/JNEUROSCI.4941-06.2007

Tenenbaum, J. B., and Griffiths, T. L. (2001). Generalization, similarity, and Bayesian inference. Behav. Brain Sci. 24, 629-640. doi: 10.1017/S0140525X01000061

Tsao, J. C. (1948). Studies in spaced and massed learning: II. Meaningfulness of material and distribution of practice. Q. J. Exp. Physiol. Cogn. Med. Sci. 1, 79-84. doi: 10.1080/17470214808416748

Veyrac, A., Sacquet, J., Nguyen, V., Marien, M., Jourdan, F., and Didier, A. (2009). Novelty determines the effects of olfactory enrichment on memory and neurogenesis through noradrenergic mechanisms. Neuropsychopharmacology 34, 786-795. doi: 10.1038/npp.2008.191

Wang, J.-H., and Feng, D.-P. (1992). Postsynaptic protein kinase C essential to induction and maintenance of long-term potentiation in the hippocampal CA1 region. Proc. Natl. Acad. Sci. U.S.A. 89, 2576-2580.

Wilson, D. A. (1995). NMDA receptors mediate expression of one form of functional plasticity induced by olfactory deprivation. Brain Res. 677, 238-242. doi: 10.1016/0006-8993(95)00151-F

Wilson, D. A. (2009). Olfaction as a model system for the neurobiology of mammalian short-term habituation. Neurobiol. Learn. Mem. 92, 199-205. doi: 10.1016/j.nlm.2008.07.010

Wilson, D. A., and Linster, C. (2008). Neurobiology of a simple memory. J. Neurophysiol. 100, 2-7. doi: 10.1152/jn.90479.2008

Wilson, D. A., and Stevenson, R. J. (2003a). The fundamental role of memory in olfactory perception. Trends Neurosci. 26, 243-247. doi: 10.1016/S01662236(03)00076-6

Wilson, D. A., and Stevenson, R. J. (2003b). Olfactory perceptual learning: the critical role of memory in odor discrimination. Neurosci. Biobehav. Rev. 27, 307-328. doi: 10.1016/S0149-7634(03)00050-2

Wolfman, C., Fin, C., Dias, M., Bianchin, M., Da Silva, R. C., Schmitz, P. K., et al. (1994). Intrahippocampal or intraamygdala infusion of KN62, a specific inhibitor of calcium/calmodulin-dependent protein kinase II, causes retrograde amnesia in the rat. Behav. Neural Biol. 61, 203-205. doi: 10.1016/S01631047(05)80001-9
Wright, G. A., and Smith, B. H. (2004). Variation in complex olfactory stimuli and its influence on odor recognition. Proc. R. Soc. Lond. B 271, 147-152. doi: 10.1098/rspb.2003.2590

Yang, G., Pan, F., and Gan, W.-B. (2009). Stably maintained dendritic spines are associated with lifelong memories. Nature 462, 920-924. doi: 10.1038/nature08577

Yuan, Q., Harley, C. W., and McLean, J. H. (2003). Mitral cell betal and 5-HT2A receptor colocalization and cAMP coregulation: a new model of norepinephrine-induced learning in the olfactory bulb. Learn. Mem. 10, 5-15. doi: $10.1101 / \mathrm{lm} .54803$

Zagrebelsky, M., and Korte, M. (2014). Form follows function: BDNF and its involvement in sculpting the function and structure of synapses. Neuropharmacology 76C, 628-638. doi: 10.1016/j.neuropharm. 2013.05.029

Zigova, T., Pencea, V., Wiegand, S. J., and Luskin, M. B. (1998). Intraventricular administration of BDNF increases the number of newly generated neurons in the adult olfactory bulb. Mol. Cell. Neurosci. 11, 234-245. doi: 10.1006/mcne.1998.0684

Zimering, J. H., and Cleland, T. A. (2011). Dihydrokainate restores recall of olfactory reward-based associative learning following impairment by isoflurane. FASEB J. 25:674.3

Zucco, G. M., Hummel, T., Tomaiuolo, F., and Stevenson, R. J. (2014). The influence of short-term memory on standard discrimination and cued identification olfactory tasks. J. Neurosci. Methods 222, 138-141. doi: 10.1016/j.jneumeth.2013.11.006

Conflict of Interest Statement: The authors declare that the research was conducted in the absence of any commercial or financial relationships that could be construed as a potential conflict of interest.

Received: 23 April 2014; accepted: 16 June 2014; published online: 07 July 2014

Citation: Tong MT, Peace ST and Cleland TA (2014) Properties and mechanisms of olfactory learning and memory. Front. Behav. Neurosci. 8:238. doi: 10.3389/fnbeh. 2014.00238

This article was submitted to the journal Frontiers in Behavioral Neuroscience. Copyright (c) 2014 Tong, Peace and Cleland. This is an open-access article distributed under the terms of the Creative Commons Attribution License (CC BY). The use, distribution or reproduction in other forums is permitted, provided the original author(s) or licensor are credited and that the original publication in this journal is cited, in accordance with accepted academic practice. No use, distribution or reproduction is permitted which does not comply with these terms. 